\title{
Potential Application of PCR Based Molecular Methods in Fish Pathogen Identification: A Review
}

\author{
Md. Ali Arman Ador ${ }^{1}$ (D), Md. Shameul Haque ${ }^{1}$, (i) , Sulav Indra Paul ${ }^{1}$, (D) , Jui \\ Chakma ${ }^{1}$, (i) , Rakib Ehsan ${ }^{1}$, (1) , Ashikur Rahman',
}

${ }^{1}$ Bangabandhu Sheikh Mujibur Rahman Agricultural University, Institute of Biotechnology and Genetic Engineering, Gazipur-1706, Bangladesh.

\section{How to cite}

Ador, M.A.A., Haque, S., Paul, S.I., Chakma, J., Ehsan, R., Rahman, A. (2022). Potential Application of PCR Based Molecular Methods in Fish Pathogen Identification: A Review. Aquaculture Studies, 22(1), AQUAST621. http://doi.org/10.4194/2618-6381/AQUAST621

\section{Article History}

Received 18 March 2021

Accepted 26 July 2021

First Online 05 August 2021

\section{Corresponding Author}

Tel.: +8801823327135

E-mail: ador.ali.arman@gmail.com

\section{Keywords}

Molecular diagnosis

PCR

RT-PCR

Multiplex-PCR

Fish pathogen

\begin{abstract}
Molecular biology developments have led to fast growth in new methods for fish disease diagnosis. Molecular diagnostic methods are rapid and more specific, more sensitive than the culture of pathogens, serology, histology, and biochemical methods which are traditionally utilized to identify causative agents of fish disease. Molecular diagnostic methods are valuable for detecting specific pathogen that are difficult to culture in vitro or require a long cultivation period and it significantly more rapid in providing results compared to culture. It enables earlier informed decision-making and rapid diagnosis of bacteremia, particularly for low levels of bacteria in specimens. Molecular techniques which have the major significance are mainly PCR-based molecular diagnostic methods including Polymerase Chain Reaction (PCR), Real-Time Polymerase Chain Reaction (RT-PCR), Multiplex Polymerase Chain Reaction (multiplexPCR), and Random Amplified Polymorphic DNA (RAPD), etc. These have been increasingly utilized to diagnose fish disease for the last recent years. Molecular diagnostic methods can detect pathogens from asymptomatic fish, so disease outbreaks could be prevented. As a consequence, antibiotic treatment can be reduced and the development of antibiotic-resistant bacteria can be eliminated. In this review paper, we attempt to summarize the potentiality of PCR-based molecular diagnostic methods and their application in fish pathogen identification.
\end{abstract}

\section{Introduction}

Aquaculture industries are major contributors to the economy of Bangladesh (Ahmed, 2013; Dey et al., 2008) as well as many countries and an increasingly important component in global food supply (Charoonnart et al., 2018). The fast expansion of aquaculture has been accompanied by the spread of infectious diseases and accountable for vital economic losses (Leung \& Bates, 2013; Tavares-Dias \& Martins, 2017). In the attempt to combat infectious diseases, biocides and antimicrobials are used worldwide, with subsequent hazardous outcomes to the environment and workers' health, and the increased chance of the emergence of resistant strains (Cabello, 2006; Defoirdt et al., 2011;). The fish diseases are a greater problem in the sustainable development of Fish culture (BondadReantaso et al., 2005) in Bangladesh as well as in the world (Rodger, 2016). Bacteria and virus are the leading causative agents of diseases (Plumb \& Hanson, 2010; Wolf, 2019) in freshwater fishes (Pridgeon \& Klesius, 2012) and marine fishes (Muroga, 2001). 
Fish disease diagnosis has progressed from the traditional approaches of isolation and phenotypic characterization of the pathogen to the modern methods of molecular biology (Austin, 2019). Traditionally, the diagnosis of the disease is operated by agar cultivation and then observation of phenotypic and serological properties of the pathogen and sometimes histological examination (Gilligan, 2013; Kumar et al., 2014). In many developing countries, fish pathogens are usually identified based on traditional biochemical identification methods (Adhikari et al., 2015; Váradi et al., 2017) which are time-consuming and most regularly could no longer confirm the pathogen specifically (Foddai \& Grant, 2020; Franco-Duarte et al., 2019). Some experiments have been made using biochemical tests, DNA homology, and protease variability (Kumar et al., 2014; Zdzalik et al., 2013), these strategies have some negative aspects such as the need for previous isolation of the pathogen and inadequate sensitivity to detect low levels of the pathogen (Altinok et al., 2008; Wakabayashi et al., 2016).

In contrast, molecular identification techniques are very robust and precise (Adzitey et al., 2013; FrancoDuarte et al., 2019) and currently practiced in different developed (Bigarré et al., 2017) and developing countries (Sarowar et al., 2019). During the last fifteen years or so, molecular methods have been increasingly more utilized to diagnose fish diseases (Altinok \& Kurt, 2003). Since molecular diagnostic strategies are quicker and greater sensitive (Dwivedi et al., 2017; Kociolek, 2017) than traditional diagnostic techniques, pathogens could be identified from asymptomatic fish resulting in prevention of diseases before an outbreaks.

Fish health management is a term utilized in aquaculture to describe management practices that are planned to avoid fish infection (Assefa \& Abunna, 2018; Opiyo et al., 2018). Once fish get in poor health it can be challenging to salvage them. Successful fish health management starts with the prevention of disease as an alternative to treatment (Francis-Floyd, 2011; Noga, 2010). Under intensive aquaculture conditions, the risk of stress increases, and a massive proportion of the stock might also come to be infected (Datta, 2012; Huntingford \& Kadri, 2014; Rehman et al., 2017). Therefore, the detection of the pathogen from carrier fish is necessary for effective fish disease management (Sadler \& Goodwin, 2007). In this aspect, the main objectives of this review are to explore the potentiality of six PCR based molecular diagnostic methods: i. PCR; ii. Multiplex-PCR; iii. RT-PCR; and iv. RAPD applied for fish pathogen identification v. Nested PCR vi Loopmediated isothermal amplification (LAMP).

\section{Glance of Molecular Diagnostic Methods}

Diagnosis is the process of identifying the disease or any abnormal condition which is explain and derived from the host's sign and symptoms. The data required for diagnosis is normally derived from a history and physical test of the host organism seeking care (Abdisa \& Abdisa, 2017; Neshati et al., 2018), sometimes, one or more diagnostic procedures like clinical tests, are also accomplished during the procedure (Balogh et al., 2015). According to Aggarwal (2015) "Diagnosis may be defined as the determination or identification of the cause or nature of an illness by evaluation and analysis of the signs, symptoms and supportive tests in an individual patient. Diagnostic criteria are a set of signs, symptoms, and tests for use in routine clinical care to guide the care of individual patients" (Aggarwal et al., 2015). According to Patrinos et al. (2017) "Molecular diagnostics is referred to as the detection of genomic variants, aiming to facilitate diagnosis, subclassification, prognosis, and monitoring response to therapy". Molecular diagnostics is the compiled result of fruitful interaction amongst laboratory medicine, genomics, and technological knowledge in the area of molecular genetics, in particular with significant discoveries in the subject of molecular genomic technologies (Dwivedi et al., 2017;). All these factors make a contribution to the identification and highquality characterization of the genetic foundation of the pathogen which, in turn, is fundamental for the accurate provision of diagnosis (Dwivedi et al., 2017). Molecular diagnostics is a series of methods used to analyze markers in the genome and proteome the individual's genetic code and how their cells express their genes as proteins by way of applying molecular biology to clinical testing (Orakpoghenor \& Markus, 2020; Shen, 2019). Molecular techniques can keep away from problems inherent in the study of organisms for which no in-vitro culture medium or technique is available, and have the possibility to significantly increase the sensitivity of detection (Francy et al., 2009; Rhoads et al., 2012). Many molecular techniques for diagnosis are available to detect the genetic variation among pathogen genes (Amjad, 2020; Procop, 2007). Such as Polymerase Chain Reaction (PCR) based are: Real-Time Polymerase Chain Reaction (RT- PCR) (Logan et al., 2009; Wong \& Medrano, 2005), Multiplex Polymerase Chain Reaction (multiplex-PCR) (Mahoney \& Chernesky, 1995;), Random Amplified Polymorphic DNA (RAPD) (Butler, 2012) etc. , and non-PCR based are: Restriction fragment length polymorphism (RFLP) (Mittal et al., 2013), the enzyme-linked immunosorbent assay (ELISA)(Drijvers et al., 2017), etc.

\section{The Potential Beneficial Role of Molecular Diagnostic Methods in Aquaculture}

Successful fish health management starts with the prevention of disease as an alternative to treatment(Faisal et al., 2017). Under intensive aquaculture conditions, the risk of disease outbreak, anti-biotic resistant bacteria, aquatic pollution, stock mortality etc. are common phenomena (Preena et al., 2020; Santos \& Ramos, 2018). Once fish get in poor health it is very challenging to manage them (Assefa \& 
Abunna, 2018). Therefore, the detection of pathogen from the host is necessary for effective fish disease management (Altinok \& Kurt, 2003; Austin, 2019).

\section{Prevention of Disease Outbreak}

The molecular method for disease detection is now a world-recognized system (Dwivedi et al., 2017). The fish pathogen can be detected accurately with the help of molecular diagnostic methods (Cai et al., 2014). In case of traditional biochemical tests, many fish pathogens cannot be detected even closely related pathogenic species cannot be differentiated (Adhikari et al., 2015; Bajinka, 2017). In most cases of aquaculture, accurate identification of causative agents of diseases is not practiced, so it is quite difficult to apply the proper management for preventing and using appropriate drugs for controlling the diseases (Assefa \& Abunna, 2018). As consequence, an outbreak of diseases occurred frequently ( Lindahl \& Grace, 2015; Sharma et al., 2012). If pathogens can be detected and recognized in the environment, for example, between harvesting and re-stocking, then this can be extremely useful in the prevention of disease outbreaks (Assefa \& Abunna, 2018; Dwivedi et al., 2017).

\section{Reducing the Chance of Developing Antibiotic- Resistant Bacteria}

Antibiotic-resistant bacteria is a burning issue in Aquaculture. The capacity of Antimicrobial resistance (AMR) genes to pass between microbes, a technique known as horizontal gene transfer (HGT), is thought to underlie the quick rise in safe pathogens seen over the globe. (Thornber et al., 2020; Watts et al., 2017). This process can happen between irrelevant bacterial species, meaning that resistance genes display in nonpathogenic, natural microbes can be exchanged to the creature or human pathogenic microbes and posture a danger to the creature and human wellbeing (Fletcher, 2015; Peterson \& Kaur, 2018; Thornber et al., 2020). Accurate diagnosis of disease allows for the selection of appropriate antimicrobials, and avoidance of antibiotics in human health (Abadi et al., 2019; Llor \& Bjerrum, 2014). Therefore, antibiotic treatment can be reduced and the development of antibiotic-resistant bacteria may also be eliminated.

\section{Other Beneficial Role of Molecular Diagnostic Methods}

Molecular methodologies offer numerous advantages to the clinical laboratory. These include:

\section{Turnaround Time}

In comparison with standard conventional culture strategies, molecular techniques ordinarily offer way better turnaround times from receipt to result announcing (Leung \& Bates, 2013; Lievens et al., 2011).

\section{Application Area}

Broader applications can be found with molecular methodologies such as infectious diseases, genetic testing, drug resistance, and tumor marker detection etc. (samples collected from fish tissue, blood, etc.) (Debnath et al., 2010; Emmadi et al., 2011; Marwal \& Gaur, 2020).

\section{PCR Based Methods in Fish Pathogen Identification}

\section{Polymerase Chain Reaction (PCR)}

In 1983, the Polymerase Chain Reaction (PCR) was discovered by Kary Mullis (Mullis et al., 1986). PCR resembles an in vitro and elementary form of DNA replication, a physiological process used by all living cells to duplicate their genetic material before cell division (Baynes \& Dominiczak, 2009).

\section{Denaturation}

DNA Template contains the sequences that will be amplified by PCR (Kalle et al., 2014). In this stage, melting temperature $(\mathrm{Tm})$ generally $92-94^{\circ} \mathrm{C}$ makes the double-stranded DNA separate into the single-stranded (Borah, 2011; Sarah Maddocks \& Jenkins, 2017).

\section{Annealing}

The short DNA fragments are called "Primers" that bind by complementary base pairing to opposite DNA strands at the annealing temperature generally $55-60^{\circ} \mathrm{C}$ (Borah, 2011; Tymoczko et al., 2011).

\section{Elongation}

DNA polymerases copy DNA molecules during the PCR reaction (Caetano-Anollés, 2013; Drouin et al., 2007). DNA polymerase is an enzyme responsible for DNA replication and only able to add nucleotides to the $5^{\prime}$ to 3' end(Cox et al., 2015).

Theoretically, the increase in the amount of product after each round will be geometric (Rimstad et al., 1990). In every cycle of PCR, approximately the amount of DNA increased to double, as well as it is repeating in the following cycle and, a new strand of DNA subsequently acts as a template for replication. This results in an exponential increase in the number of targeted segments of DNA during PCR. A total of 25-40 PCR cycles is carried out and depending on the expected yield of the PCR products (Baynes \& Dominiczak, 2009). Usually, at least a millions copy of a particular region of a DNA molecule can be produced and the PCR product can be detected via gel electrophoresis (McPhearson et al., 1991). The amplified product may then be used for analytical detection, sizing, cloning, or sequencing (Wages, 2005). 


\section{Major Advantages of PCR}

PCR method is valuable for detecting specific pathogens that are difficult to culture in vitro or require a long cultivation period (Yamamoto, 2002) and it significantly more rapid in providing results compared to culture. It enables earlier informed decision-making by the rapid diagnosis of bacteremia, particularly for low levels of bacteria in specimens (Maurer et al., 2017). It is useful in detecting cases in extrapulmonary specimens which may be missed by smear and/or culture (Narayana et al., 2018). PCR is still considered an adjunct test for certain diagnostic tests that still rely on smear and culture (Yang \& Rothman, 2004).

\section{Disadvantages of PCR}

PCR still need culture for testing for drug/antibiotic susceptibility and genetic typing (Cockerill, 1999). PCR results should not be used as the sole basis of a patient treatment management decision. All results should be interpreted by a trained professional in conjunction with the review of the patient's history and clinical signs and symptoms. False-negative results can arise from improper sample collection/transport, an insufficient amount of specimen, degradation of nucleic acids (typically RNA) during shipping or storage, detecting organisms representative of normal flora near specimen collection site, acid-fast bacilli in water, and contaminants in the lab, specimen mix-up, etc (Narayana et al., 2018).

\section{Application of PCR to Identify Fish Pathogens}

A lot of Polymerase chain reaction (PCR) assays are already developed to identify the specific fish pathogen (Table 1), e.g. a fish pathogen Vibrio harveyi can be detected by a specific primer set.

\section{Multiplex Polymerase Chain Reaction (multiplex-PCR)}

Multiplex polymerase chain reaction (Multiplex $P C R$ ) alludes to the utilize of polymerase chain response to intensify a few diverse DNA arrangements at the same time (as in case performing numerous isolated PCR responses all together in one reaction) (Kechin et al., 2020; Markoulatos et al., 2002). Multiplex-PCR was first described in 1988 as a method to detect deletions in the dystrophin gene (Chamberlain et al., 1988). In multiplex $\mathrm{PCR}$, two or more primer sets planned for the expansion of diverse targets are included within the same PCR reaction. (Shen, 2019a). This technique intensifies DNA in tests utilizing numerous primers and a temperaturemediated DNA polymerase in a warm cycler (Lorenz, 2012). The preliminary plan for all primer sets should be optimized so that all primer sets can work at the same annealing (strengthening) temperature amid PCR (Sint et al., 2012). The multiplex polymerase chain reaction is a widespread molecular technique utilized for the amplification of multiple targets in just one PCR experiment (Rollinson \& Hay, 2012; Zebardast et al., 2014).

\section{Advantages of Multiplex- Polymerase Chain Reaction (multiplex-PCR)}

In multiplex PCR Less input material is required and provides more information (Elnifro et al., 2000). It is Cost effective (fewer dNTPs, enzymes, and other consumables) (Mahony et al., 2009) and time-saving (versus conventional culture methods) (Giantsis et al., 2017). It has increased accuracy of data analysis and fewer pipetting errors (Lee et al., 2007). It can be used to identify exonic and intronic sequences in specific genes (Hernandez-Rodriguez, 2012).

\section{Disadvantages of Multiplex- Polymerase Chain Reaction (multiplex-PCR)}

The self-inhibition among different sets of primers can be occurred. In this PCR, it is important the design of primers because they must be characterized by adherence to specific DNA sequences at similar temperatures. However, it may require several trials to achieve the standardization of the procedure (Jackson et al., 2004).

Application Multiplex- polymerase chain reaction (multiplex-PCR) in fish pathogen detection:

Numerous Multiplex- polymerase chain reaction (multiplex-PCR) assays are already examined and studied to detect the fish pathogenic bacteria and viruses (Table 2), such as Aeromonas hydrophila, Edwardsiella tarda and Photobacterium damselae can be detected in a single run of PCR by using multiple sets of primers. Fish pathogenic virus like infectious pancreatic necrosis virus (IPNV), infectious hematopoietic necrosis virus (IHNV), and viral hemorrhagic septicemia virus (VHSV) can be identified by multiplex PCR (Williams et al., 1999)

\section{Real-Time Polymerase Chain Reaction (RT- PCR)}

In the area of molecular diagnostics, real-time PCRbased assays have acquired favor in the recent past (Gunson et al., 2006; Mackay, 2007). A real-time polymerase chain reaction (real-time PCR), additionally recognized as quantitative Polymerase Chain Reaction (qPCR), is a laboratory technique of molecular biologybased totally on the polymerase chain response (PCR) (Foroni et al., 2017; García-Giménez et al., 2019; Mauger \& Deleuze, 2019). It observes the amplification of a targeted DNA molecule in the course of the PCR (i.e., in real-time), not at its end, as in conventional PCR. Realtime PCR can be used quantitatively (quantitative realtime PCR) (Kralik \& Ricchi, 2017). Real-time PCR is carried out in a thermal cycler with the ability to illuminate every sample with a beam of light of at least one particular wavelength and realize the fluorescence 
Table 1. A shortlist of pathogen-specific primers used in polymerase chain reaction (PCR) methods to identify fish pathogens

\begin{tabular}{|c|c|c|c|}
\hline Fish Pathogen & Host & Primer's name and sequence & References \\
\hline \multirow[t]{4}{*}{ Vibrio parahaemolyticus } & Shrimp & Forward: AP4-F1- 5'ATGAGTAACAATATAAAACATGAAAC3' & (Dangtip et al., \\
\hline & & Reverse: AP4-R1- 5'ACGATTTCGACGTTCCCCAA3' & 2015) \\
\hline & & Forward: AP4-F2-5'TTGAGAATACGGGACGTGGG3' & \\
\hline & & Reverse: AP4-R2 5'GTTAGTCATGTGAGCACCTTC3' & \\
\hline \multirow[t]{6}{*}{ Koi herpesvirus (KHV) } & Koi, Goldfish, & Forward: KHV-F-5'GACGACGCCGGAGACCTTGTG3', & (Meyer et al., \\
\hline & Common Carp & Reverse: KHV-R- 5'CACAAGTTCAGTCTGTTCCTCAAC3' & 2012) \\
\hline & & Forward: KHV-TKf 5'GGGTTACCTGTACGAG3' & \\
\hline & & Reverse: KHV-TKr 5'CACCCAGTAGATTATGC3' & \\
\hline & & Forward: KHV-Gray-2F- 5'GACACCACATCTGCAAGGAG3' & \\
\hline & & Reverse: KHV-Gray-2R-5'GACACATGTTACAATGGTGGC3' & \\
\hline \multirow[t]{2}{*}{ Vibrio harveyi } & Sea bream & Forward: 5'GAGTTCGGTTTCTTTCAAG3' & (Haldar et al., \\
\hline & & Reverse: 5'TGTAGTTTTTCGCTAATTTC3' & 2010) \\
\hline \multirow[t]{2}{*}{ Pseudomonas aeruginosa } & Freshwater culture & Forward: 5'ATGGAAATGCTGAAATTCGGC3' & (Tripathy et al., \\
\hline & system & Reverse: 5'CTTCTTCAGCTCGACGCGACG3' & 2007) \\
\hline \multirow[t]{2}{*}{ Renibacterium salmoninarum } & Salmon & Forward: 5'GATCGTGAAATACATCAAG3' & (León et al., 1994) \\
\hline & & Reverse: 5'GGATCGTGTTTI'ATCCACCC3' & \\
\hline \multirow[t]{2}{*}{ Tenacibaculum soleae } & Senegalese sole fish, & Forward: G47F- 5'ATGCTAATATGTGGCATCAC3' & (López et al., 2011) \\
\hline & $\begin{array}{c}\text { Wedge sole fish, Brill, } \\
\text { Turbot }\end{array}$ & Reverse: G47R- 5'CGTAATTCGTAATTAACTTTGT3' & \\
\hline \multirow{6}{*}{$\begin{array}{l}\text { Flavobacterium } \\
\text { psychrophilum }\end{array}$} & Rainbow trout, coho & $1^{\text {st }}$ step & (Wiklund et al., \\
\hline & salmon, eel (Anguilla & Forward: 20F- 5' AGAGTTTGATCATGGCTCAG3' & 2000) \\
\hline & anguilla), Cyprinids, & Reverse: 1500R- 5' GGTTACCTTGTTACGACTT3' & \\
\hline & Pale chub & $2^{\text {nd }}$ step & \\
\hline & & Forward: PSY1-5'GTTGGCATCAACACACT3' & \\
\hline & & Reverse: PSY2-5'CGATCCTACTTGCGTAG3' & \\
\hline Aeromonas & Salmonids & Forward: 27f-5'GAGTTTGATCCTGGCTCAG-3' & (Byers et al., 2002) \\
\hline \multirow{7}{*}{ salmonicida } & & Reverse: 1492r-5'TACGGYTACCTTGTTACGACTT3' & \\
\hline & & Forward: PAAS1 -5'CGTTGGATATGGCTCTTCCT -3' & \\
\hline & & Reverse: PAAS2 -5'CTCAAAACGGCTGCGTACCA3' & \\
\hline & & Forward: AP1 -5'GGCTGATCTCTTCATCCTCACCC3' & \\
\hline & & Reverse: AP2 -5'CAGAGTGAAATCTACCAGCGGTGC3' & \\
\hline & & Forward: MIY1-5'AGCCTCCACGCGCTCACAGC3' & \\
\hline & & Reverse: MIY2-5'AAGAGGCCCCATAGTGTGGG3' & \\
\hline \multirow[t]{2}{*}{ Tenacibaculum soleae } & Turbot, Dover sole, & Forward: Sol-Fw-5'TGCTAATATGTGGCATCACAA3' & (García-González \\
\hline & $\begin{array}{l}\text { Senegalese sole, Sea } \\
\text { bass, Atlantic salmon, } \\
\text { Coho salmon }\end{array}$ & Reverse: Sol-Rv-5'CAACCCATAGGGCAGTCATC3' & et al., 2011) \\
\hline \multirow[t]{2}{*}{ Vibrio anguillarum } & Several fishes & Forward: van-ami8-5'ACAT CATCCATTTGTTAC3' & (Hong et al., 2007) \\
\hline & & Reverse: van-ami417-5'CCTTATCACTATCCAAATTG3' & \\
\hline Flavobacterium & Rainbow & Forward: FP1 -5'GTTAGTrGGCATCAACAC3' & (Urdaci et al., \\
\hline \multirow{3}{*}{ psychrophilum } & Trout, Salmonids & Reverse: FP2-5'TCGATCCTACTTGCGTAG3' & 1998) \\
\hline & & Forward: 5'AGAGTTTGATCATGGCTCAG3' & \\
\hline & & Reverse: FP2-5'CGGTTACCTTGTTACGACTT3' & \\
\hline \multirow[t]{4}{*}{ Myxobolus cerebralis } & Salmonids, Brown & Forward: Tr5-17-5'GCCCTATTAACTAGTTGGTAGTATAGAAGC3' & (Andree et al., \\
\hline & Trout, Rainbow Trout, & Reverse: Myx18-996R-5'GCGGTCTGGGCAAATGC3' & 1998; Eszterbauer \\
\hline & Gibel Carp & Forward: Tr3-17-5'GGCACACTACTCCAACACTGAATTTG3' & et al., 2019; Kelley \\
\hline & & Reverse: Myx18-909f-R-5'TGCTGTAACTGAATAACATTCAGTCAAAG3' & et al., 2004) \\
\hline \multirow[t]{4}{*}{ Sphaerothecum destruens } & Salmonids & Forward: Sd-1F-5'CGACTTTTCGGAAGGGATGTATT3' & (Mendonca \& \\
\hline & & Reverse: Sd-1R -5'AGTCCCAAACTCGACGCACACT3' & Arkush, 2004) \\
\hline & & Forward: Sd-2F -5'CCCTCGGTTTCTTGGTGATTCATAATAACT3' & \\
\hline & & Reverse: Sd-2R -5'CTCGTCGGGGCAAACACCTC3' & \\
\hline Amyloodinium ocellatum & Several marine fishes & Forward: Dino5'UF-5'CAACCTGGTGATCCTGCCAGT3' & (Levy et al., 2007) \\
\hline & & Reverse: ITSR -5'TCCCTGTTCATTCGCCATTAC3' & \\
\hline & & Forward: AO18SF1 -5'GACCTTGCCCGAGAGGG3' & \\
\hline & & Reverse: A018SR1-5'GAAAGTGTGGTGAATCTTAAC3' & \\
\hline Myxobolus pseudodispar & Cyprinid fish & Forward: Tub16SF-5'AACGGCCGCGGTATCCTG3' & (Beauchamp et al., \\
\hline & & Reverse: Tub16SR-5'TAARCCAACATYGAGGTGCCA3' & 2001; Marton \& \\
\hline & & Forward: MpF1-5'TGTGCTTCTGGTGCGTCTGC3' & Eszterbauer, 2012) \\
\hline & & Reverse: PseudoR-5'AAGCACCGAAGCACAGTCAA3' & \\
\hline $\begin{array}{l}\text { Ascaridoidea (Anisakis } \\
\text { pegreffi, A. physeteris, A. } \\
\text { simplex, Contracaecum }\end{array}$ & $\begin{array}{l}\text { Several freshwater } \\
\text { and marine fishes }\end{array}$ & $\begin{array}{l}\text { Forward: NC5-5'GTAGGTGAACCTGCGGAAGGATCATT3' } \\
\text { Reverse: NC2-5'TTAGTTTCTTTTCCTCCGCT3' }\end{array}$ & $\begin{array}{l}\text { (Kijewska et al., } \\
\text { 2002; Zhu et al., } \\
\text { 1998) }\end{array}$ \\
\hline osculatum, $C$. radiatum, $C$. & & & \\
\hline rudolphi, Hysterothylacium & & & \\
\hline aduncum Porrocaecum & & & \\
\hline angusticolle, $P$. crassum, $P$. & & & \\
\hline $\begin{array}{l}\text { depressum, and } P . \\
\text { ensicaudatum) }\end{array}$ & & & \\
\hline Anisakid Nematodes & Black scabbardfish, & Forward: Primer A- & (Pontes et al., \\
\hline & Chub mackerel, Blue & 5'GTCGAATTCGTAGGTGAACCTGCGGAAGGATCA3' & 2005) \\
\hline & & Reverse: Primer B1-5'GCCGGATCCGAATCCTGGTTAGTTTCTTTTCCT3' & \\
\hline Gyrodactylus sp. & Rainbow trout, & Forward: ITS1F-5'GTTTC CGTAG GTGAA CCT3' & (Rokicka et al., \\
\hline & $\begin{array}{l}\text { Brown trout, Salmon, } \\
\text { Grayling }\end{array}$ & Reverse: ITS2R-5'GGTAA TCACG CTTGAATC3' & 2007) \\
\hline
\end{tabular}


emitted by using the excited fluorophore (Ahrberg et al., 2016). The PCR technique usually consists of a sequence of temperature changes that are repeated 25-50 times (Chen et al., 2019). The recommended temperature and the duration for RT-PCR used for every cycle depend on a variety of parameters and factors, such as the concentration of divalent ions, the enzyme used to synthesize the DNA, deoxyribonucleotides (dNTPs) in the reaction, and the annealing temperature of the primers, etc. (Sambrook, 2001; Shaheen Shahzad et al., 2020; van Pelt-Verkuil et al., 2008).

\section{Advantages of Real-Time Polymerase Chain Reaction (RT- PCR)}

Real-time PCR is not influenced by non-specific amplification (Dorak, 2007). This assay required less amount of the template material (Staahlberg et al., 2005). The major advantage over the other PCR technique is the quantification and it quantifies the template DNA or RNA present in the sample (Tom et al., 2004). By this method, amplification can be monitored in real-time (Mackay et al., 2002) and it enables high

Table 2. A shortlist of Multiplex Polymerase chain reaction (multiplex-PCR) assay used to detect fish pathogens.

\begin{tabular}{|c|c|c|c|c|}
\hline Host & Fish pathogen & $\begin{array}{c}\text { Target gene of } \\
\text { pathogen }\end{array}$ & Primer name and sequences & References \\
\hline \multirow[t]{8}{*}{ Sea bream } & Red sea bream & RNRS gene & Forward: VF- 5'GCATGTATGCTGTTTAGACA3' & (Jeong et al., \\
\hline & iridoviruses (RSIV) & & Reverse : VR- 5'GAGCATCAAGCAGGCGATCT3' & 2004) \\
\hline & & ATPase gene & Forward: 3F- 5'CAAACCACAGCGCGGCAAGT3' & \\
\hline & & & Reverse : 3R- 5'AGTAGCGCACCATGTCCTCC3' & \\
\hline & & DPOL gene & Forward: 4F- 5'CGGGGGCAATGACGACTACA3' & \\
\hline & & & Reverse : 4R- 5'CCGCCTGTGCCTTTTCTGGA3' & \\
\hline & & Pst I fragment & Forward: 1F- 5'CTCAAACACTCTGGCTCATC3' & \\
\hline & & & Reverse : 1R- 5'GCACCAACACATCTCCTATC3' & \\
\hline \multirow[t]{6}{*}{ Rainbow trout } & Lactococcus garvieae & Internal & Forward: Lg F- 5'ACTTTATTCAGTTTTGAGGGGTCT3' & (Chapela et al., \\
\hline & & $\begin{array}{c}\text { transcribed } \\
\text { spacer gene (ITS) }\end{array}$ & Reverse : Lg R- 5'TTTAACGTCTTCGTTGACCAGA3' & $\begin{array}{l}\text { 2018; Keeling et } \\
\text { al., 2012; }\end{array}$ \\
\hline & Yersinia ruckeri & glnA gene & Forward: YR gInA F-5'TCCAGCACCAAATACGAAGG3' & Marancik \& \\
\hline & & & Reverse : YR gInA R-5'ACATGGCAGAACGCAGATC3' & Wiens, 2013) \\
\hline & Flavobacterium & Unknown protein & Forward: Fp Sig F-5'GGTAGCGGAACCGGAAATG3' & \\
\hline & psychrophilum & & Reverse : Fp Sig R-5'TTTCTGCCACCTAGCGAATACC3' & \\
\hline \multirow{6}{*}{$\begin{array}{l}\text { Yellow } \\
\text { croaker }\end{array}$} & Vibrio alginolyticus & Collagenase gene & Forward: VA-F-5'CGAGTACAGTCACTTGAAAGCC3' & (Liu et al., 2016) \\
\hline & & & Reverse : VA-R-5'CACAACAGAACTCGCGTTACC3' & \\
\hline & Vibrio & Collagenase gene & Forward: VP-F-5'GAAAGTTGAACATCAGCACGA3' & \\
\hline & parahaemolyticus & & Reverse : VP-R-5'GGTCAGAATCAAACGCCG3' & \\
\hline & Vibrio harveyi & ToxR & Forward: VH-F-5'GAAGCACTCACCGAT3' & \\
\hline & & & Reverse: VH-R-5'GGTGAAGACTCAGCA3' & \\
\hline \multirow{8}{*}{$\begin{array}{l}\text { Tilapia, } \\
\text { Japanese eel, } \\
\text { Flounders }\end{array}$} & Aeromonas & $16 s$ rRNA & Forward: Ah-F- 5'GTAATGCCTGGGAAAT3' & (Chang et al., \\
\hline & hydrophila & & Reverse : Ah-R- 5'TTGATACGTATAGGCA3' & 2009) \\
\hline & Edwardsiella tarda & & Forward: Et-F- 5'ACGTAACGTCGCAAGA3' & \\
\hline & & & Reverse : Et-R- 5'CCGTGTATATACAGGA3' & \\
\hline & Photobacterium & & Forward: Pd-F- 5'GCTTGAATACATTCGAG3' & \\
\hline & damselae & & Reverse : Pd-R- 5'CACCTTTCGGTCTTGCT3' & \\
\hline & Streptococcus iniae & & Forward: Si-F- 5'CACTAATCCAAAGAGTT3' & \\
\hline & & & Reverse : Si-R- 5'TTAGGCGGCTGGCTCCTAA3' & \\
\hline \multirow[t]{10}{*}{ Rainbow trout } & Renibacterium & unknown & Forward: Rs1-5'CAAGGTGAAGGGAATTCTTCCACT3' & (Altinok et al., \\
\hline & salmoninarum & & Reverse: Rs2-5'GACGGCAATGTCCGTTCCCGGTTT3' & $\begin{array}{c}\text { 2008; Brown et al., } \\
\text { 1994) }\end{array}$ \\
\hline & Aeromonas & & Forward: AH1-5'GAAAGGTTGATGCCTAATACGTA3' & (Altinok et al., \\
\hline & hydrophila & & Reverse: AH2-5'CGTGCTGGCAACAAAGGACAG3' & $\begin{array}{c}\text { 2008; Nielsen et } \\
\text { al., 2001) }\end{array}$ \\
\hline & Yersinia ruckeri & & Forward: YerF-5'GCGAGGAGGAAG GGTTAAGTG3' & (Altinok et al., \\
\hline & & & Reverse: YerR-5'GAA GGCACCAAGGCATCTCTG-3' & $2001,2008)$ \\
\hline & Aeromonas & & Forward: ASF-5'CGTTGGATATGGCTCTTCCT3' & (Altinok et al., \\
\hline & salmonicida & & Reverse: ASR-5'CTCAAAACGGCTGCGTA3' & $\begin{array}{c}\text { 2008; Hiney et al., } \\
\text { 1992) }\end{array}$ \\
\hline & Flavobacterium & & Forward: FCF-5'AAGGCAACGATGGGTAG3' & (Altinok et al., \\
\hline & columnare & & Reverse: 161B-5'GCACGGAGTTAGCCGATC3' & $\begin{array}{c}\text { 2008; Yeh et al., } \\
\text { 2006) }\end{array}$ \\
\hline \multirow{7}{*}{$\begin{array}{l}\text { Brown trout, } \\
\text { grayling, pike, } \\
\text { and whitefish }\end{array}$} & Infectious Pancreatic & VP2 gene & Forward: WB1-5'CCGCAACTTACTTGAGATCCATTATGC3' & (Williams et al., \\
\hline & Necrosis Virus (IPNV) & & Reverse: WB2-5'CGTCTGGTTCAGATTCCACCTGTAGTG3' & 1999) \\
\hline & Infectious & Ngene & Forward: IHN3-5GTTCAACTTCAACGCCAACAGG3' & \\
\hline & Hematopoietic & & Reverse: IHN4-5'TGAAGTACCCCACCCCGAGCATCC3' & \\
\hline & Necrosis Virus (IHNV) & & & \\
\hline & Viral Hemorrhagic & G gene & Forward: VHS3-5'CGGCCAGCTCAACTCAGGTGTCC3' & \\
\hline & $\begin{array}{c}\text { Septicemia Virus } \\
\text { (VHSV) }\end{array}$ & & Reverse: VHS4-5'CCAGGTCGGTCCTGATCCATTCTGTC3' & \\
\hline
\end{tabular}


confidence detection of low copy targets. It needs no post PCR processing (Hanna et al., 2005).

\section{Disadvantages of Real-Time Polymerase Chain Reaction (RT- PCR)}

Real-time PCR (RT-PCR) technique will only indicate the presence of antigenic material during infection and will not indicate if a host was infected. It needs specialized bio-containment laboratories, operated by highly trained technicians, which makes it an expensive test and difficult to scale. Real-time PCR (RT-PCR) kits are not available for all kind of genes and disorders and the technical and standardized protocols are limited. Furthermore, higher expertise and technical skills are required for developing an RT-PCR assay.

\section{Application Real-Time Polymerase Chain Reaction (RT- PCR) in Fish Pathogen Detection}

RT-PCR has been increasingly utilized to identify fish pathogens (both virus and bacteria) since the beginning of the twenty-first century (Table 3), e.g. Tilapia lake virus (TiLV) can be detected by real-time PCR.

\section{Random Amplified Polymorphic DNA (RAPD)}

It is a PCR-based technique, however, the difference is segments of DNA that are randomly amplified (Kumari \& Thakur, 2014; Zia et al., 2020). The scientist performing RAPD creates numerous arbitrary, short primers normally 10 bp (range can be 8-12 nucleotides sometimes more than that) (Rocco et al., 2014; Shekhawat et al., 2019), then operated with the PCR, the usage of a large template of genomic DNA, hoping that fragments will be amplified (Arora et al., 2013). By resolving the resulting patterns, a semi-unique to a unique profile can be picked up from an RAPD reaction (Galanis et al., 2015). Unlike standard PCR analysis, RAPD does no longer requires any precise understanding of the DNA sequence of the target organism (Galanis et al., 2015; Martín et al., 2014). The segment of DNA, whether it will be amplified or not, it depends on positions of primers (generally identical 10mer) which are complementary to DNA sequences (Premkrishnan \& Arunachalam, 2012). For example, no fragment will produce if primers are annealed too far distance from opposite annealed primer or they are not facing each other which means they are in the same direction (Clark et al., 2019; Hommelsheim et al., 2014).

\section{Advantages of Random Amplified Polymorphic DNA (RAPD)}

It requires no DNA probes and sequence information for the design of specific primers (Hadrys et al., 1992). It involves no blotting or hybridization steps, hence, it is quick, simple and efficient (Kumar \&
Gurusubramanian, 2011). It requires only small amounts of DNA (about $10 \mathrm{ng}$ per reaction) and the procedure can be automated (Kumar \& Gurusubramanian, 2011). It produces a high number of fragments (Rieseberg, 1996). Additional findings supported the use of RAPD analysis as an effective tool in species identification and crosscontamination test among different cell lines (Guo et al., 2001). The RAPD-PCR method can be applied to detect genetic diversity and similarity in numerous organisms using various primers (Andrighetto et al., 2001; Berthier \& Ehrlich, 1999). For all of these reasons, the RAPD assay has been used to construct phylogenetic trees for resolving taxonomic problems in many organisms (Chalmers et al., 1992).

\section{Disadvantages of Random Amplified Polymorphic DNA (RAPD)}

Nearly all RAPD markers are dominant (Lynch \& Milligan, 1994), i.e. it is not possible to distinguish whether a DNA segment is amplified from a locus that is heterozygous (1 copy) or homozygous (2 copies). Codominant RAPD markers, observed as different-sized DNA segments amplified from the same locus, are detected only rarely (Kumar \& Gurusubramanian, 2011). The RAPD technique is notoriously laboratorydependent and needs carefully developed laboratory protocols to be reproducible (Caliskan, 2012). Mismatches between the primer and the template may result in the total absence of PCR product as well as in a merely decreased amount of the product (Caliskan, 2012). RAPD results can be difficult to interpret and lack of prior knowledge on the identity of the amplification products. It has problems with reproducibility (sensitive to changes in the quality of DNA, PCR components and PCR conditions). Gel electrophoresis can separate DNA quantitatively, cannot separate equal-sized fragments qualitatively (i.e. according to base sequence) (Nandani \& Thakur, 2014).

\section{Application RAPD in Fish Pathogen Detection}

Comparing to other PCR-based molecular diagnostic methods, a few RAPD has been studied to identify fish pathogens (Table 4), e.g. marine fish pathogen Tenacibaculum maritimum can be identified by using RAPD.

\section{Nested PCR}

Nested PCR is an improved adaptation of PCR designed to enhance the sensitivity and specificity of the procedure (Shen et al., 2019; Carr et al., 2010). At first Kamolvarin (1993) described the nested PCR method. Nested PCR entails the employment of two primer sets and two PCR reactions in succession. The first set of primers is used in an initial PCR reaction and is designed to anneal to sequences upstream from the second set of primers. The first PCR reaction's amplicons are utilized 
Table 3. A shortlist of real time polymerase chain reaction (RT-PCR) assay used for fish pathogen identification

\begin{tabular}{|c|c|c|c|}
\hline Fish pathogen & Host & Primer name and sequences & References \\
\hline $\begin{array}{l}\text { Infectious } \\
\text { myonecrosis virus } \\
\text { (IMNV) }\end{array}$ & Shrimp & $\begin{array}{l}\text { Forward: IM-MCP3571-3592F- 5'CGCGCCAGTCTTTCCATTTAGT3' } \\
\text { Reverse : IM-MCP3688-3706R- 5'CCAATGTTCGAGCACCCTC3' } \\
\text { Forward: IM-MCP3572-3593F- 5'GCGCCAGTCTTTCCATTCAGTG3' } \\
\text { Reverse: IM-MCP3698-3716R- 5'CCAATGTTCGAGCACCCTC3' }\end{array}$ & $\begin{array}{c}\text { (Kokkattunivarthil et } \\
\text { al., 2018) }\end{array}$ \\
\hline $\begin{array}{l}\text { Tilapia lake virus } \\
\text { (TiLV) }\end{array}$ & $\begin{array}{l}\text { Tilapia, White leg } \\
\text { shrimp }\end{array}$ & $\begin{array}{l}\text { Forward: Nested ext-1- TATGCAGTACTTTCCCTGCC3' } \\
\text { Forward: ME1- 5'GTTGGGCACAAGGCATCCTA3' } \\
\text { Reverse : 7450/150R/ME2- 5'TATCACGTGCGTACTCGTTCAGT3' } \\
\text { Forward: TiLV-Seg1-F- 5'TCATTCGCCTATATAGTTAC3' } \\
\text { Reverse : TiLV-Seg1-R-5'TTAATTACGCACTATTACTG3' } \\
\text { Forward: TiLV-Seg5-F- 5'TTTTTCTCAGTTACCACTC3' } \\
\text { Reverse : TiLV-Seg5-R- 5'TTATCTCAGACTCCAATAGC3' } \\
\text { Forward: TiLV-Seg9-F- 5'ACGTCCTTAAAGTCATACTT3' } \\
\text { Reverse : TiLV-Seg9-R- 5'ACAAGTCCGATTACTTTTTC3' }\end{array}$ & $\begin{array}{l}\text { (Dong et al., 2017; } \\
\text { Eyngor et al., 2014, } \\
\text { 2014) }\end{array}$ \\
\hline $\begin{array}{l}\text { Viral hemorrhagic } \\
\text { septicemia virus } \\
\text { (VHSV) }\end{array}$ & $\begin{array}{l}\text { Olive flounder, } \\
\text { Rainbow trout, } \\
\text { Turbot }\end{array}$ & $\begin{array}{l}\text { Forward: VHSV-Universal-F- 5'GWGGAGARGGACGGGTRCTTGT3' } \\
\text { Reverse : VHSV- universal-R- 5'TCTGTCACCTTGATCCCCTCCAG3' } \\
\text { Forward: VHSV-I-F- 5'AGAGTGACTTATCGAGTCACCTGTTCG3' } \\
\text { Reverse : VHSV-I-R-5'GAACAGGTGTCCTTCTAGTGTTTCCGAC3' } \\
\text { Forward: VHSV-IV-F- 5'TCCATCCTTATTTCCATGAGAGGAGAAGGA3' } \\
\text { Reverse : VHSV-IV-R- 5'TCCAGTAGACTCCTTGCCAGTGGGTTG3' }\end{array}$ & (Hwang et al., 2018) \\
\hline Vibrio harveyi & $\begin{array}{l}\text { Seabass, } \\
\text { shrimps, } \\
\text { mollusks, } \\
\text { crustaceans }\end{array}$ & $\begin{array}{l}\text { Forward: mreB11F- 5'TGAAGCTGTGATCAACTACG3' } \\
\text { Reverse : mreB9bisR- 5'CCTGACAGTGGCTCTTGTAA3' } \\
\text { Forward: Vh. topA-F- 5'TGGCGCAGCGTCTATACG3' } \\
\text { Reverse : Vh.topA-R- 5'TATTTGTCACCGAACTCAGAACC3' } \\
\text { Forward: toxRF1- 5'GAAGCAGCACTCACCGAT3' } \\
\text { Reverse : toxRR1- 5'GGTGAAGACTCATCAGCA3' }\end{array}$ & $\begin{array}{l}\text { (BAILLIE et al., 2015; } \\
\text { Mougin et al., 2020; } \\
\text { Pang et al., 2006) }\end{array}$ \\
\hline $\begin{array}{l}\text { Streptococcus } \\
\text { agalactiae }\end{array}$ & Nile tilapia & $\begin{array}{l}\text { Forward: 5'CATTTGCGTCTTGTTAGTTTTGAG3' } \\
\text { Reverse : 5'GGAGCCTAGCGGATCGA3' }\end{array}$ & (Asencios et al., 2016) \\
\hline $\begin{array}{l}\text { Enteromyxum } \\
\text { scophthalmi }\end{array}$ & Turbot & $\begin{array}{l}\text { Forward: ENTEROMYX F- 5'GGCTTAATTTGACTCAACA3' } \\
\text { Reverse : ENTEROMYX R- 5'CTCCACCAACTAAGAACG3' }\end{array}$ & (Alonso et al., 2015) \\
\hline $\begin{array}{l}\text { Francisella } \\
\text { noatunensis } \\
\text { subsp. orientalis }\end{array}$ & $\begin{array}{l}\text { Tilapia, Atlantic } \\
\text { cod Atlantic } \\
\text { Salmon, Striped } \\
\text { bass, Ornamental } \\
\text { cichlids }\end{array}$ & $\begin{array}{l}\text { Forward: iglC- 5'GGGCGTATCTAAGGATGGTATGAG3' } \\
\text { Reverse: igIC-5'AGCACAGCATACAGGCAAGCTA3' } \\
\text { Probe: FAM-5'ATCTATTGATGGGCTCACAACTTCACAA3' BHQ-1 }\end{array}$ & (Soto et al., 2010) \\
\hline $\begin{array}{l}\text { Ichthyophthirius } \\
\text { multifiliis }\end{array}$ & $\begin{array}{l}\text { Several } \\
\text { freshwater fishes }\end{array}$ & $\begin{array}{l}\text { Forward: IMRf1- 5' AGTGACAAGAAATAGCAAGCCAGGAG3' } \\
\text { Reverse: IMRr1-5' ACCCAGCTAAATAGGCAGAAGTTCAA3' }\end{array}$ & (Jousson et al., 2005) \\
\hline $\begin{array}{l}\text { Ceratomyxa } \\
\text { shasta }\end{array}$ & Salmonid fishes & $\begin{array}{l}\text { Forward: Cs-1034F- 5'CCAGCTTGAGATTAGCTCGGTAA3' } \\
\text { Reverse: Cs-1104R-5'CCCCGGAACCCGAAAG3' } \\
\text { Probe: } 1058 \text { ' 6-FAM-CGAGCCAAGTTGGTCTCT CCGTGAAAACTA-MRA }\end{array}$ & $\begin{array}{c}\text { (Hallett \& } \\
\text { Bartholomew, 2006) }\end{array}$ \\
\hline $\begin{array}{l}\text { Anisakids } \\
\text { (nematodes) }\end{array}$ & $\begin{array}{l}\text { Several marine } \\
\text { fishes }\end{array}$ & $\begin{array}{l}\text { Forward: COI F- 5'GGKCYATTAAYTYTATRACWACTAC3' } \\
\text { Reverse: COI R -5'AAAGAWGTATTMARRTTACGRTCVG3' } \\
\text { Probe: COI PROBE- FAM-TCTATTTCTTTGGARCAYA-TAM }\end{array}$ & (Herrero et al., 2011) \\
\hline Ichthyobodo spp. & $\begin{array}{l}\text { Salmon, Halibut, } \\
\text { and several } \\
\text { fishes }\end{array}$ & $\begin{array}{l}\text { Forward: CosF1-5'AATAGGAGGTCTGCGAACG3' } \\
\text { Forward: CosF2 -5'CCTGAGAAACAGCTACCACT3' } \\
\text { Reverse: CosR4 -5'CCGAGCGGTCTAAGAATTTC3' } \\
\text { Reverse: CosR5-5'TTCCTGTACTGGTAAGGTTCC3' } \\
\text { Forward: Costia F-5'ACGAACTTATGCGAAGGCA3' } \\
\text { Reverse: Costia R-5'TGAGTATTCACTYCCGATCCAT3' } \\
\text { Probe: Costia (FAM)- 5' TCCACGACTGCAAACGATGACG-3' (TAMRA) }\end{array}$ & (Isaksen et al., 2012) \\
\hline $\begin{array}{l}\text { Myxobolus } \\
\text { cerebralis }\end{array}$ & $\begin{array}{l}\text { Rainbow trout, } \\
\text { Salmonid }\end{array}$ & $\begin{array}{l}\text { Forward: Tr5-3-5'CGTGAGACTGCGGACGGCTCAG3' } \\
\text { Reverse: Tr3-1-5'CGGTGTGTACAAAGGGCAGGGAC3' } \\
\text { Forward: Tr5-6-5'GGCAGCGTTAAAACTGTCTCACG3' } \\
\text { Reverse: Tr3-6-5'CCTCACAGTCTCTCCATGACAC3' } \\
\text { Forward: MX5-5'CTGCGGACGGCTCAGTAAATCAGT3' } \\
\text { Reverse: MX3-5'CCAGGACATCTTAGGGCATCACAGA3' } \\
\text { Forward: Tr5-16-5'GCATTGGTITACGCTGATGTAGCGA3' } \\
\text { Reverse: Tr5-17-5'GCCCTATTAACTAGTTGGTAGTATAGAAGC3' } \\
\text { Forward: Tr3-16-5'GAATCGCCGAAACAATCATCGAGCTA3' } \\
\text { Reverse: Tr3-17-5'GGCACACTACTCCAACACTGAMTTG3' }\end{array}$ & $\begin{array}{l}\text { (Andree et al., 1997, } \\
\text { 1998; Kelley et al., } \\
\text { 2006) }\end{array}$ \\
\hline $\begin{array}{l}\text { Thelohanellus } \\
\text { kitauei, }\end{array}$ & Carp & $\begin{array}{l}\text { Forward: UEP-F-5'ACCTGGTTGATCCTGCCAG3' } \\
\text { Reverse: UEP-R-5'CTTCCGCAGGTTCACCTACGG3' } \\
\text { Forward: TkF-1-5'GCCCAGTAATCTACTATTCGACG3' } \\
\text { Reverse: TkR-1-5'GCTATTGATCTGTTAATCCTATC3' }\end{array}$ & $\begin{array}{c}\text { (Barta et al., 1997; Seo } \\
\text { et al., 2012) }\end{array}$ \\
\hline Anisakis pegreffii, & $\begin{array}{l}\text { Crustaceans } \\
\text { (Krill), Fish and } \\
\text { Squids }\end{array}$ & $\begin{array}{l}\text { Forward: RTpegF-5'CTTTTGGAGGTTGATAATCG3' } \\
\text { Reverse: RTpegR-5'CCCACAAATCTCTGAACATT3' } \\
\text { Probe: pegHyPr-5'CTTGGGCTTTGCCTAGGATGTC3' (6FAM/BHQ) }\end{array}$ & (Paoletti et al., 2018) \\
\hline A. simplex & & $\begin{array}{l}\text { Forward: RTsimf-5'CTTTAATTTTGGTTGCTCAGAT3' } \\
\text { Reverse: RTsimR-5'CGATTATCAACCTCCAAAAG3' } \\
\text { Probe: simHyPr-5'ATGACCAGTGACTTTCACAGTCAAAT3' (5-CY/BBQ) }\end{array}$ & \\
\hline $\begin{array}{l}\text { Pseudoterranova } \\
\text { decipiens, }\end{array}$ & & $\begin{array}{l}\text { Forward: RTdecF-5'GGCTTGATAAATTTGGACAG3' } \\
\text { Reverse: RTdecR-5'ATAAAATACCTCTCATAGCATCC3' } \\
\text { Probe: decHyPr-5'CTTCCGGCGATGTAATTCAT3' (YAK/BHQ) }\end{array}$ & \\
\hline P. bulbosa & & $\begin{array}{l}\text { Forward: RTbulF-5'CTGGTCATCARTGGTATTGA3' } \\
\text { Reverse: RTbulR-5'CCTCTCATAGCATCCAACTT3' } \\
\text { Probe: bulHyPr-5'ACAACCGTTGTGTTGTTCCTT3' (6FAM/BHQ) }\end{array}$ & \\
\hline P. krabbei & & $\begin{array}{l}\text { Forward: RTkraF-5'GTTGATCAGTTGGAGTTGG3' } \\
\text { Reverse: RTkraR-5'CAAATCTCAGAACACTGACC3' } \\
\text { Probe: kraHyPr-5'TTCTTGGGCTTTGCCTAGAA3' (LC640/BHQ) }\end{array}$ & \\
\hline $\begin{array}{l}\text { Hysterothylacium } \\
\text { aduncum }\end{array}$ & & $\begin{array}{l}\text { Forward: RThystF-5'ATTTGACTATCAAGGTAACTGGT3' } \\
\text { Reverse: RThystR-5'TTAATAGCCATTCTAGGCAAA3' } \\
\text { Probe: hystHyPr-5'GATCACACAACGGTTATCCACCTCT3' (YAK/BHQ) }\end{array}$ & \\
\hline
\end{tabular}


as a template for a second set of primers and a second amplification step (Shen et al., 2019). With this approach, the sensitivity and specificity of DNA amplification might be greatly improved.

\section{Advantages of Nested PCR}

The first and most efficient point of nested PCR is that the specificity and sensitivity were higher than those of conventional PCR methods (Liop et al., 2000). Another benefit of nested PCR is that it uses less target DNA (Liop et al., 2000). It can also help with the amplification of low-abundance genes.

\section{Disadvantages of Nested PCR}

However, adding a second amplification step and manipulating previously amplified material at the same time could result in a large rise in false positives due to cross contamination, making this strategy too precarious for routine analysis (Liop et al., 2000).

\section{Application of Nested PCR in Fish Pathogen Detection}

Nested PCR has been used as a viable tool for the detection of pathogens causing fish diseases where a single round of PCR is insufficient. Researchers around the globe have successfully developed nested PCR protocols for the identification of perilous fish pathogens including Vibrio vulnificu, Ranibacterium salmoninarum, Flavobacterium psychrophilum,
Flavobacterium columnare, Tenacibaculum maritimum, Photobacterium damselae, Myxobolus cerebralis (Andree et al., 1998), Tenacibaculum maritimum (Avendaño-Herrera et al., 2004), Flavobacterium columnare (Bader et al., 2003), Enterocytozoon salmonis (Barlough et al., 1995), microsporidium seriolae (Bell et al., 1999), Flexibacter maritimus (Cepeda et al. 2003), Cyprinid herpesvirus-3 (El-Matbouli et al., 2007), Flavobacterium psychrophilum (Izumi et al., 2005), Pseudomonas plecoglossicida (Izumi et al., 2007), Sphaerothecum destruens (Men- donca and Arkush 2004), Myxobolus cerebralis (Skirpstunas et al., 2006), Flavobacterium psychrophilum (Wiklund et al., 2000) etc (Jimenez et al., 2011; Baliarda et al., 2002; Osorio et al., 1999; Osorio et al., 2000; Chase and Pascho, 1998; Arias et al., 1995)

\section{Loop-Mediated Isothermal Amplification (LAMP)}

Loop-mediated isothermal amplification (LAMP) is a DNA amplification technique introduced in the year 2000 that amplifies DNA with high specificity, efficiency and rapidity under isothermal conditions (Notomi et al., 2000). The LAMP reaction uses a DNA polymerase with high strand displacement activity and pairs of specially designed inner and outer primers. At the three prime terminal, each of the inner primers has a sequence that is complementary to one chain of the amplification region and identical to the inner region of the same chain at the five prime terminal. Using the aforementioned stem loop areas as a stage, DNA

Table 4. A short list of Random Amplified Polymorphic DNA (RAPD) assay used for fish pathogen identification

\begin{tabular}{|c|c|c|c|}
\hline Host & Pathogen & Primer name and sequences & References \\
\hline $\begin{array}{l}\text { Sea bream, Sea } \\
\text { bass }\end{array}$ & $\begin{array}{l}\text { Photobacterium } \\
\text { damselae subsp. } \\
\text { piscicida (Vibrionaceae) }\end{array}$ & $\begin{array}{c}\text { RAPD: AA- 5'GGTGTCGGGCTACCACTACGGG3' RAPD: BC- } \\
\text { 5'ACCACTTCGGGTTTCATGCCC3' }\end{array}$ & $\begin{array}{l}\text { (Dalla Valle et al., } \\
\text { 2002) }\end{array}$ \\
\hline Salmonid fish & Aeromonas salmonicida & $\begin{array}{l}1^{\text {st }} \text { step, RAPD: A05-5'AGCAGCGCCTCA3' } \\
2^{\text {nd }} \text { step, Forward primer: 5'AGCCTCCACGCGCTCACAGC3' } \\
\text { Reverse primer: 5'AAGAGGCCCCATAGTGTGGG3' }\end{array}$ & $\begin{array}{l}\text { (Inglis \& Aoki, } \\
\text { 1996) }\end{array}$ \\
\hline $\begin{array}{l}\text { Yellowtail, } \\
\text { Rainbow trout }\end{array}$ & Lactococcus garvieae & 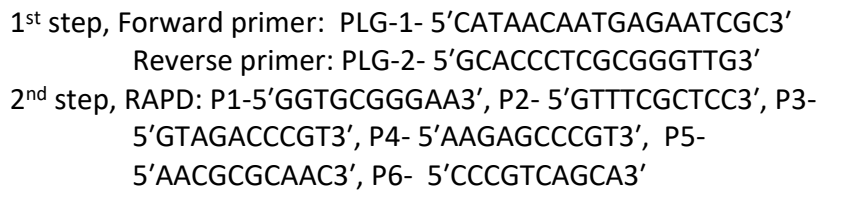 & $\begin{array}{l}\text { (Ravelo et al., } \\
\text { 2003) }\end{array}$ \\
\hline $\begin{array}{l}\text { Turbot, } \\
\text { Salmon, Sole, } \\
\text { Gilthead } \\
\text { seabream }\end{array}$ & $\begin{array}{l}\text { Tenacibaculum } \\
\text { maritimum }\end{array}$ & $\begin{array}{c}\text { RAPD: P1- 5'GGTGCGGGAA3', P2- 5'GTTTCGCTCC3', P3- } \\
\text { 5'GTAGACCCGT3', P4- 5'AAGAGCCCGT3', P5- } \\
\text { 5'AACGCGCAAC3', P6- 5'CCCGTCAGCA3' }\end{array}$ & $\begin{array}{l}\text { (Avendaño- } \\
\text { Herrera et al., } \\
\text { 2004) }\end{array}$ \\
\hline Trout, Salmon & $\begin{array}{l}\text { Aeromonas salmonicida } \\
\text { and Aeromonas } \\
\text { hydrophila }\end{array}$ & $\begin{array}{l}\text { RAPD: A05- 5'AGCAGCGCCTCA3', A07- 5'TGCCTCGCACCA3', A09- } \\
\text { 5'CCGCAGTTAGAT3' }\end{array}$ & $\begin{array}{l}\text { (Miyata et al., } \\
\text { 1995) }\end{array}$ \\
\hline $\begin{array}{l}\text { Rainbow trout, } \\
\text { Coho salmon }\end{array}$ & $\begin{array}{l}\text { Flavobacterium } \\
\text { psychrophilum }\end{array}$ & $\begin{array}{l}\text { RAPD: Primer 1- 5'TTCGCAGATCCCAACAACAA3', Primer 2- } \\
\text { 5'CTAAGTACCGCCCCGATC3' }\end{array}$ & $\begin{array}{l}\text { (Crump et al., } \\
\text { 2001) }\end{array}$ \\
\hline $\begin{array}{l}\text { Trout } \\
\text { and Carp }\end{array}$ & Argulus sp. & $\begin{array}{l}\text { RAPD: OPA4-5'AATCGGGCTG3', OPA11-5'CAATCGCCGT3', OPA14- } \\
\text { 5'TCTGTGCTGG3', OPC11-5'AAAGCTGCGG3', OPC15- } \\
\text { 5'GACGGATCAG3', OPC19-5'GTTGCCAGCC3', OPH11- } \\
\text { 5'CTTCCGCAGT3', OPY2-5'CATCGCCGCA3', OPY20- } \\
\text { 5'AGCCGTGGAA3' }\end{array}$ & $\begin{array}{l}\text { (Sahoo et al., } \\
\text { 2013) }\end{array}$ \\
\hline
\end{tabular}


polymerase-mediated strand-displacement synthesis repeats the elongation events in a sequential manner. This approach works on the basis of producing a large number of DNA amplification products with a mutually compatible sequence and an alternating, repeating structure.

\section{Advantages of LAMP}

LAMP is very easy and simple method to execute as soon as the suitable primers are prepared, requiring a DNA polymerase, four primers and a regular laboratory water bath or heat block for reaction. Moreover, it is extremely precise for the target sequence and amplifies DNA with high efficiency producing $10^{9}$ copies of target sequence less than an hour. Another benefit of LAMP is that it may efficiently amplify RNA sequences when used in conjunction with reverse transcription.

\section{Disadvantages of LAMP}

LAMP is less versatile than conventional PCR. Kermekchiev et al. (2009) found lower sensitivity of LAMP than PCR in case of complex sample like blood. Due to difficulty in proper primer designing, LAMP is not useful for cloning purposes but for useful as a diagnostic or detection technique (Torres et al., 2011).

\section{Application of LAMP in Fish Pathogen Detection}

In the investigation of fish diseases, LAMP has been employed frequently due to its advantageous context over other PCR based techniques. Rapid screening of different fish pathogenic bacteria including Edwardsiella ictaluri (Yeh et al., 2005), Flavobacterium columnare (Yeh et al., 2006), Nocardia seriolae (Itano et al., 2006), Vibrio anguillarum (Kulkarni et al., 2009; Gao et al., 2010) Yersinia ruckeri (Saleh et al., 2008), Lactococcus garvieae (Tsai et al., 2013), Streptococcus inae (Zhou et al., 2018), Myxobolus cerebralis (El-Matbouli and Soliman 2005a), Tetracapsuloides bryosalmonae (ElMatbouli and Soli- man 2005b), koi herpes virus (Gunimaladevi et al., 2004), hematopoietic necrosis virus (Gunimaladevi et al., 2005), Edwardsiella tarda (Savan et al., 2004), spring viraemia of carp virus (Shivappa et al. 2008), viral hemorrhagic septicaemia virus (Soliman et al., 2006) were executed engaging LAMP technique.

\section{Conclusion}

In case of disease outbreaks, quick diagnosis and rapid removal of infected fish are necessary for the successful implementation of effective control and health management strategies in aquaculture. Past diagnostic methods tend to be expensive, laborintensive, time-consuming, and might not lead to a specific diagnosis, even when compared with histological evidence. PCR-based molecular diagnostic methods help to prevent disease outbreaks and reducing the potentiality of producing antibiotics resistant microorganisms. It has the capacity for rapid, sensitive diagnosis even it can detect pathogen from asymptomatic fishes. The main aim of the PCR-based molecular diagnostic methods are epidemiological studies as well as identifying causes of disease outbreaks and identifying the presence of pathogens. In recent years, the number of new publications describing new molecular techniques has increased significantly. These publications demonstrate the development of new molecular diagnostic methods that appear very promising and useful. This is the high time to wide-scale adoption and application of PCR based molecular diagnostic methods.

\section{Ethical Statement}

This study does not require ethical statement.

\section{Funding Information}

The funders had no role in preparation of the manuscript.

\section{Author Contribution}

MAAA has searched and contributed in writing this article. MAAA, MSH, SIP, JC, RE and AR have designed the paper structure and contributed to editing and revising the article. All authors read and approved the final manuscript.

\section{Conflict of Interest}

The authors declare that they have no known competing financial or non-financial, professional, or personal conflicts that could have appeared to influence the work reported in this paper.

\section{Acknowledgements}

This paper does not contain any acknowledgements.

\section{References}

Abadi, A.T.B., Rizvanov, A.A., Haertlé, T., \& Blatt, N.L. (2019). World Health Organization report: Current crisis of antibiotic resistance. BioNanoScience, 9(4), 778-788.

Abdisa, T., \& Abdisa*, T. (2017). Review on Practical Guidance of Veterinary Clinical Diagnostic Approach. International Journal of Veterinary Science and Research, 3(1), 030049. https://doi.org/10.17352/ijvsr.000020

Adams, A., \& Thompson, K.D. (2011). Development of diagnostics for aquaculture: Challenges and opportunities. Aquaculture Research, 42, 93-102.

Adhikari, H., Ali, M.Y., Shahiduzzaman, M., Shams, F.I., \& Sarower, M.G. (2015). Biochemical and PCR assay for detection of pathogenic bacteria at shrimp and shrimp 
farms in Bangladesh. Fisheries and Aquaculture Journal, $6(2), 1$.

Adzitey, F., Huda, N., \& Ali, G.R.R. (2013). Molecular techniques for detecting and typing of bacteria, advantages and application to foodborne pathogens isolated from ducks. 3 Biotech, 3(2), 97-107. https://doi.org/10.1007/s13205-012-0074-4

Aggarwal, R., Ringold, S., Khanna, D., Neogi, T., Johnson, S.R., Miller, A., Brunner, H.I., Ogawa, R., Felson, D., Ogdie, A., Aletaha, D., \& Feldman, B.M. (2015). Distinctions Between Diagnostic and Classification Criteria? Arthritis Care \& Research, 67(7), 891-897. https://doi.org/10.1002/acr.22583

Ahmed, N. (2013). Linking prawn and shrimp farming towards a green economy in Bangladesh: Confronting climate change. Ocean \& Coastal Management, 75, 33-42.

Ahrberg, C.D., Ilic, B.R., Manz, A., \& Neužil, P. (2016). Handheld real-time PCR device. Lab on a Chip, 16(3), 586-592.

Alberts, B., Johnson, A., Lewis, J., Raff, M., Roberts, K., \& Walter, P. (2002). DNA Replication Mechanisms. Molecular Biology of the Cell. 4th Edition. https://www.ncbi.nlm.nih.gov/books/NBK26850/

Alliance, G., \& District of Columbia Department of Health. (2010). Diagnosis of a Genetic Disease. In Understanding Genetics: A District of Columbia Guide for Patients and Health Professionals. Genetic Alliance. https://www.ncbi.nlm.nih.gov/books/NBK132142/

Alonso, M., Lago, F.C., Gómez-Reino, M., Fernández Casal, J., Martín Varela, I., Vieites, J.M., \& Espiñeira, M. (2015). Non-invasive fast real-time PCR assay for detection of the enteric parasite $E$ nteromyxum scophthalmi in cultured turbot ( $S$ cophthalmus maximus L.). Aquaculture Research, 46(9), 2104-2115.

Altinok, i., \& Kurt, i. (2003). Molecular diagnosis of fish diseases: A review. Turkish Journal of Fisheries and Aquatic Sciences, 3(2), 131-138.

Altinok, I., Capkin, E., \& Kayis, S. (2008). Development of multiplex PCR assay for simultaneous detection of five bacterial fish pathogens. Veterinary Microbiology, 131(3-4), 332-338.

Altinok, I., Grizzle, J.M., \& Liu, Z. (2001). Detection of Yersinia ruckeri in rainbow trout blood by use of the polymerase chain reaction. Diseases of Aquatic Organisms, 44(1), 29-34.

Aly, S.M. (2013). A review of fish diseases in the Egyptian aquaculture sector: Working report.

Amjad, M. (2020). An overview of the molecular methods in the diagnosis of gastrointestinal infectious diseases. International Journal of Microbiology, 2020.

Andree KB, MacConnell E, Hedrick RP (1998) A nested polymerase chain reaction for the detection of genomic DNA of Myxobolus cerebralis in rain- bow trout Oncorhynchus mykiss. Diseases of Aquatic Organisms 34, 145-154

Andree, K.B., Gresoviac, S.J., \& HEDRICK, R.P. (1997). Small subunit ribosomal RNA sequences unite alternate actinosporean and myxosporean stages of Myxobolus cerebralis the causative agent of whirling disease in salmonid fish. Journal of Eukaryotic Microbiology, 44(3), 208-215.

Arias, C.R., Garay, E., Aznar, R. (1995) Nested PCR method for rapid and sensitive detection of Vibrio vulnificus in fish, sediments, and water. Applied and Environmental Microbiology. 61, 3476-3478.

Arora, D.K., Das, S., \& Sukumar, M. (2013). Analyzing microbes:
Manual of molecular biology techniques/Dilip Kumar Arora, Surajit Das, Mesapogu Sukumar, editors. Heidelberg; New York: Springer.

Asencios, Y.O., Sánchez, F.B., Mendizábal, H.B., Pusari, K.H., Alfonso, H.O., Sayán, A.M., Figueiredo, M.A.P., Manrique, W.G., de Andrade Belo, M.A., \& Chaupe, N.S. (2016). First report of Streptococcus agalactiae isolated from Oreochromis niloticus in Piura, Peru: Molecular identification and histopathological lesions. Aquaculture Reports, 4, 74-79.

Assefa, A., \& Abunna, F. (2018). Maintenance of fish health in aquaculture: Review of epidemiological approaches for prevention and control of infectious disease of fish. Veterinary Medicine International, 2018.

Austin, B. (2019). Methods for the diagnosis of bacterial fish diseases. Marine Life Science \& Technology, 1(1), 41-49.

Avendaño-Herrera, R., Magariños, B., Toranzo, A.E., Beaz, R., Romalde, J.L. (2004) Species-specific polymerase chain reaction primer sets for the diag-nosis of Tenacibaculum maritimum infection. Diseases of Aquatic Organisms 62, 75-83

Avendaño-Herrera, R., Rodríguez, J., Magariños, B., Romalde, J.L., \& Toranzo, A.E. (2004). Intraspecific diversity of the marine fish pathogen Tenacibaculum maritimum as determined by randomly amplified polymorphic DNAPCR. Journal of Applied Microbiology, 96(4), 871-877.

Babady, N.E., Lee, Y.J., Papanicolaou, G., \& Tang, Y.-W. (2019). Impacts and Challenges of Advanced Diagnostic Assays for Transplant Infectious Diseases. In Principles and Practice of Transplant Infectious Diseases (pp. 795-818). Springer.

Bader JA, Shoemaker CA, Klesius PH (2003) Rapid detection of columnaris disease in channel catfish (Ictalurus punctatus) with a new species-specific 16-S rRNA genebased PCR primer for Flavobacterium columnare. Journal of Microbiological Methods 52, 209-220

Baillie, B.K., Andreakis, N., Cano-Gomez, A., Hoj, L., \& Owens, L. (2015). A multiplex PCR-based protocol for identification and quantification of Vibrio harveyirelated species. Null.

Bajinka, O. (2017). Conventional Microbiological Approaches in Identification of Pathogenic Bacteria and Protozoons Isolated from the Drinking Water of Gambian Province. SF J Appl Microbiol, 1(1).

Baliarda, A., Faure, D., \& Urdaci, M.C. (2002) Development and application of a nested PCR to monitor brood stock salmonid ovarian fluid and spleen for detection of the fish pathogen Flavobacterium psychrophilum. Journal of Applied Microbiology. 92, 510-516.

Balogh, E.P., Miller, B.T., Ball, J.R., Care, C. on D.E. in H., Services, B. on H.C., Medicine, I. of, \& The National Academies of Sciences, E. (2015). The Diagnostic Process. In Improving Diagnosis in Health Care. National Academies Press https://www.ncbi.nlm.nih.gov/books/NBK338593/

Barta, J.R., Martin, D.S., Liberator, P.A., Dashkevicz, M., Anderson, J.W., Feighner, S.D., Elbrecht, A., PerkinsBarrow, A., Jenkins, M.C., \& Danforth, H.D. (1997). Phylogenetic relationships among eight Eimeria species infecting domestic fowl inferred using complete small subunit ribosomal DNA sequences. The Journal of Parasitology, 262-271.

Bartlett, J.M., \& Stirling, D. (2003a). A short history of the polymerase chain reaction. In PCR protocols (pp. 3-6). Springer. 
Bartlett, J.M., \& Stirling, D. (2003b). PCR protocols (Vol. 226). Springer.

Basu, C. (2015). PCR primer design. Springer.

Baynes, J., \& Dominiczak, M.H. (2009). Medical biochemistry. Elsevier Health Sciences.

Bazaldua, O.V., \& Schneider, F.D. (1999). Evaluation and Management of Dyspepsia. American Family Physician, 60(6), 1773.

Beauchamp, K.A., Kathman, R.D., McDowell, T.S., \& Hedrick, R.P. (2001). Molecular phylogeny of tubificid oligochaetes with special emphasis on Tubifex tubifex (Tubificidae). Molecular Phylogenetics and Evolution, 19(2), 216-224.

Bell AS, Yokoyama H, Aoki T, Takahashi M, Maruyama K (1999) Single and nested polymerase chain reaction assays for the detection of Microspori- dium seriolae (Microspora), the causative agent of 'Beko' disease in yellow- tail Seriola quinqueradiata. Diseases of Aquatic Organisms 37, 127-134

Bigarré, L., Lesne, M., Lautraite, A., Chesneau, V., Leroux, A., Jamin, M., Boitard, P.M., Toffan, A., Prearo, M., \& Labrut, S. (2017). Molecular identification of iridoviruses infecting various sturgeon species in Europe. Journal of Fish Diseases, 40(1), 105-118.

Blanco, M.M., Gibello, A., \& Fernández-Garayzábal, J.F. (2000). Influence of fish health management: Bases, procedures and economic implications. Cahiers Options Méditerranéennes, 51, 45-49.

Bondad-Reantaso, M.G., Subasinghe, R.P., Arthur, J.R., Ogawa, K., Chinabut, S., Adlard, R., Tan, Z., \& Shariff, M. (2005). Disease and health management in Asian aquaculture. Veterinary Parasitology, 132(3-4), 249-272.

Borah, P. (2011). Primer designing for PCR. Science Vision, 11(3), 134-136.

Brown, L.L., Iwama, G.K., Evelyn, T.P.T., Nelson, W.S., \& Levine, R.P. (1994). Use of the polymerase chain reaction (PCR) to detect DNA from Renibacterium salmoninarum within individual salmonid eggs. Diseases of Aquatic Organisms, 18(3), 165-171.

Butler, J.M. (2012). Chapter 16-Non-human DNA. In J.M. Butler (Ed.), Advanced Topics in Forensic DNA Typing: Methodology (pp. 473-495). Academic Press. https://doi.org/10.1016/B978-0-12-374513-2.00016-6

Byers, H.K., Gudkovs, N., \& Crane, M.S.J. (2002). PCR-based assays for the fish pathogen Aeromonas salmonicida. I. Evaluation of three PCR primer sets for detection and identification. Diseases of Aquatic Organisms, 49(2), 129-138.

Cabello, F.C. (2006). Heavy use of prophylactic antibiotics in aquaculture: A growing problem for human and animal health and for the environment. Environmental Microbiology, 8(7), 1137-1144.

Cabello, F.C., Godfrey, H.P., Tomova, A., Ivanova, L., Dölz, H., Millanao, A., \& Buschmann, A.H. (2013). Antimicrobial use in aquaculture re-examined: Its relevance to antimicrobial resistance and to animal and human health. Environmental Microbiology, 15(7), 1917-1942.

Caetano-Anollés, D. (2013). Polymerase chain reaction.

Cai, H.Y., Caswell, J.L., \& Prescott, J.F. (2014). Nonculture molecular techniques for diagnosis of bacterial disease in animals: A diagnostic laboratory perspective. Veterinary Pathology, 51(2), 341-350.

Caliskan, M. (2012). Genetic diversity in microorganisms. BoDBooks on Demand.
Carol, G.R., Jeyasanta, K.I., Mani, A.E., \& Patterson, J. (2013). Prevalence of Pseudomonas sp. in Fin Fishes and their Antibiotic Susceptibility. Journal of Pure and Applied Microbiology, 7(1), 677-681.

Carr, J., Williams, D.G., \& Hayden, R.T. (2010). Molecular detection of multiple respiratory viruses. In Molecular diagnostics (pp. 289-300). Academic Press.

Cepeda C, García-Márquez S, Santos Y (2003) Detection of Flexibacter ma- ritimus in fish tissue using nested PCR amplification. Journal of Fish Dis- eases 26, 65-70

Chamberlain, J.S., Gibbs, R.A., Rainer, J.E., Nguyen, P.N., \& Thomas, C. (1988). Deletion screening of the Duchenne muscular dystrophy locus via multiplex DNA amplification. Nucleic Acids Research, 16(23), 1114111156.

Chang, C.-I., Wu, C.-C., Cheng, T.C., Tsai, J.-M., \& Lin, K.-J. (2009). Multiplex nested-polymerase chain reaction for the simultaneous detection of Aeromonas hydrophila, Edwardsiella tarda, Photobacterium damselae and Streptococcus iniae, four important fish pathogens in subtropical Asia. Aquaculture Research, 40(10), 11821190.

Chapela, M.-J., Ferreira, M., Varela, C., Arregui, L., \& GarridoMaestu, A. (2018). Development of a multiplex real-time PCR method for early diagnosis of three bacterial diseases in fish: A real-case study in trout aquaculture. Aquaculture, 496, 255-261.

Charoonnart, P., Purton, S., \& Saksmerprome, V. (2018). Applications of microalgal biotechnology for disease control in aquaculture. Biology, 7(2), 24.

Chase, D.M., \& Pascho, R.J. (1998) Development of a nested polymerase chain reaction for amplification of a sequence of the p57 gene of Renibacterium salmoninarum that provides a highly sensitive method for detection of the bacterium in salmonid kidney. Diseases of Aquatic Organisms. 34, 223-229.

Chen, R., Lu, X., Li, M., Chen, G., Deng, Y., Du, F., Dong, J., Huang, X., Cui, X., \& Tang, Z. (2019). Polymerase Chain Reaction using "V" Shape Thermal Cycling Program. Theranostics, 9(6), 1572.

Clark, D.P., Pazdernik, N.J., \& McGehee, M.R. (2019). Chapter 6-Polymerase Chain Reaction. In D.P. Clark, N.J. Pazdernik, \& M.R. McGehee (Eds.), Molecular Biology (Third Edition) (pp. 168-198). Academic Cell. https://doi.org/10.1016/B978-0-12-813288-3.00006-9

Cockerill, F.R. (1999). Genetic Methods for Assessing Antimicrobial Resistance. Antimicrobial Agents and Chemotherapy, 43(2), 199-212.

Coll, J.M., \& Dominguez-Juncal, J. (1995). Applications of monoclonal antibodies in aquaculture. Biotechnology Advances, 13(1), 45-73.

Council, N.R. (n.d.). Committee on Diagnosis and Control of Johne's Disease. 2003. Diagnosis and control of Johne's disease. National Academies Press, Washington, DC.

Cox, M.M., Doudna, J., \& O'Donnell, M. (2015). Molecular Biology: Principles and Practice. Macmillan Higher Education.

Crump, E.M., Perry, M.B., Clouthier, S.C., \& Kay, W.W. (2001). Antigenic characterization of the fish pathogen Flavobacterium psychrophilum. Applied and Environmental Microbiology, 67(2), 750-759.

Dalla Valle, L., Zanella, L., Belvedere, P., \& Colombo, L. (2002). Use of random amplification to develop a PCR detection method for the causative agent of fish pasteurellosis, Photobacterium damselae subsp. Piscicida 
(Vibrionaceae). Aquaculture, 207(3-4), 187-202.

Dangtip, S., Sirikharin, R., Sanguanrut, P., Thitamadee, S., Sritunyalucksana, K., Taengchaiyaphum, S., Mavichak, R., Proespraiwong, P., \& Flegel, T.W. (2015). AP4 method for two-tube nested PCR detection of AHPND isolates of Vibrio parahaemolyticus. Aquaculture Reports, 2, 158162.

Datta, S. (2012). Management of water quality in intensive aquaculture. Respiration, 6, 602.

Debnath, M., Prasad, G.B., \& Bisen, P.S. (2010). Molecular diagnostics: Promises and possibilities. Springer Science \& Business Media.

Defoirdt, T., Sorgeloos, P., \& Bossier, P. (2011). Alternatives to antibiotics for the control of bacterial disease in aquaculture. Current Opinion in Microbiology, 14(3), 251-258.

Dey, M.M., Bose, M.L., \& Alam, M.F. (2008). Recommendation domains for pond aquaculture: Country case study: development and status of freshwater aquaculture in Bangladesh.

Dong, H.T., Siriroob, S., Meemetta, W., Santimanawong, W., Gangnonngiw, W., Pirarat, N., Khunrae, P., Rattanarojpong, T., Vanichviriyakit, R., \& Senapin, S. (2017). Emergence of tilapia lake virus in Thailand and an alternative semi-nested RT-PCR for detection. Aquaculture, 476, 111-118.

Dorak, M.T. (2007). Real-time PCR. Taylor \& Francis.

Doyle, M.P., Loneragan, G.H., Scott, H.M., \& Singer, R.S. (2013). Antimicrobial resistance: Challenges and perspectives. Comprehensive Reviews in Food Science and Food Safety, 12(2), 234-248.

Drijvers, J.M., Awan, I.M., Perugino, C.A., Rosenberg, I.M., \& Pillai, S. (2017). The Enzyme-Linked Immunosorbent Assay: The Application of ELISA in Clinical Research. In Basic Science Methods for Clinical Researchers (pp. 119133). Elsevier.

Drouin, R., Dridi, W., \& Samassekou, O. (2007). DNA Polymerases for PCR Applications. In Industrial Enzymes (pp. 379-401). Springer.

Dwivedi, S., Purohit, P., Misra, R., Pareek, P., Goel, A., Khattri, S., Pant, K.K., Misra, S., \& Sharma, P. (2017). Diseases and Molecular Diagnostics: A Step Closer to Precision Medicine. Indian Journal of Clinical Biochemistry, 32(4), 374-398. https://doi.org/10.1007/s12291-017-0688-8

El-Matbouli M, Rucker U, Soliman H (2007) Detection of Cyprinid herpes- virus-3 (CyHV-3) DNA in infected fish tissues by nested polymerase chain reaction. Diseases of Aquatic Organisms 78, 23-28

El-Matbouli M, Soliman H (2005a) Development of a rapid assay for the diag- nosis of Myxobolus cerebralis in fish and oligochaetes using loop-mediated isothermal amplification. Journal of Fish Diseases 28, 549-557

El-Matbouli, M., Soliman, H. (2005b) Rapid diagnosis of Tetracapsuloides bryo-salmonae, the causative agent of proliferative kidney disease (PKD) in sal- monid fish by a novel DNA amplification method, loop-mediated isothermal amplification (LAMP). Parasitology Research 96, 277-284

Elnifro, E.M., Ashshi, A.M., Cooper, R.J., \& Klapper, P.E. (2000). Multiplex PCR: Optimization and application in diagnostic virology. Clinical Microbiology Reviews, 13(4), 559-570.

Emmadi, R., Boonyaratanakornkit, J.B., Selvarangan, R., Shyamala, V., Zimmer, B.L., Williams, L., Bryant, B., Schutzbank, T., Schoonmaker, M.M., \& Wilson, J.A.A.
(2011). Molecular methods and platforms for infectious diseases testing: A review of FDA-approved and cleared assays. The Journal of Molecular Diagnostics, 13(6), 583604.

Eom, K.S., Rim, H.-J., \& Jeon, H.-K. (2020). Taenia asiatica: Historical overview of taeniasis and cysticercosis with molecular characterization. In Advances in parasitology (Vol. 108, pp. 133-173). Elsevier.

Eszterbauer, E., Sipos, D., Szakály, Á., \& Herczeg, D. (2019). Distinctive site preference of the fish parasite Myxobolus cerebralis (Cnidaria, Myxozoa) during host invasion. Acta Veterinaria Hungarica, 67(2), 212-223.

Eyngor, M., Zamostiano, R., Tsofack, J.E.K., Berkowitz, A., Bercovier, H., Tinman, S., Lev, M., Hurvitz, A., Galeotti, M., \& Bacharach, E. (2014). Identification of a novel RNA virus lethal to tilapia. Journal of Clinical Microbiology, 52(12), 4137-4146.

Faisal, M., Samaha, H., \& Loch, T.P. (2017). Chapter 9Planning a Fish-Health Program. In G. Jeney (Ed.), Fish Diseases (pp. 221-248). Academic Press. https://doi.org/10.1016/B978-0-12-804564-0.00009-0

Farahani, A. Safaie; Taghavi, S.M.; Taher-Khani, K., 2015. Comparison of conventional, nested and real-time pcr for detection of the causal agent of ratoon stunt in Iran. Journal of Plant Pathology. 97(2), 259-263.

Faruk, M.A.R., Sarker, M.M.R., Alam, M.J., \& Kabir, M.B. (2004). Economic loss from fish diseases on rural freshwater aquaculture of Bangladesh. Pakistan Journal of Biological Sciences, 7(12), 2086-2091.

Fletcher, S. (2015). Understanding the contribution of environmental factors in the spread of antimicrobial resistance. Environmental Health and Preventive Medicine, 20(4), 243-252.

Foddai, A.C., \& Grant, I.R. (2020). Methods for detection of viable foodborne pathogens: Current state-of-art and future prospects. Applied Microbiology and Biotechnology, 104(10), 4281-4288.

Foroni, L., Reid, A.G., Gerrard, G., Toma, S., \& Hing, S. (2017). 8-Molecular and Cytogenetic Analysis. In B.J. Bain, I. Bates, \& M.A. Laffan (Eds.), Dacie and Lewis Practical Haematology (Twelfth Edition) (pp. 126-164). Elsevier. https://doi.org/10.1016/B978-0-7020-6696-2.00008-4

Francis-Floyd, R. (2011). Mycobacterial infections of fish. Southern Regional Aquaculture Center USA.

Francis-Floyd, R., \& Wellborn, T.L. (1991). Introduction to fish health management. Florida Cooperative Extension Service, Institute of Food and Agricultural ....

Franco-Duarte, R., Černáková, L., Kadam, S., S. Kaushik, K., Salehi, B., Bevilacqua, A., Corbo, M.R., Antolak, H., Dybka-Stępień, K., Leszczewicz, M., Relison Tintino, S., Alexandrino de Souza, V.C., Sharifi-Rad, J., Melo Coutinho, H.D., Martins, N., \& Rodrigues, C.F. (2019). Advances in Chemical and Biological Methods to Identify Microorganisms-From Past to Present. Microorganisms, 7(5), 130. https://doi.org/10.3390/microorganisms7050130

Francy, D.S., Bushon, R.N., Brady, A.M., Bertke, E.E., Kephart, C.M., Likirdopulos, C.A., Mailot, B.E., Schaefer, F.W., \& Lindquist, Hda. (2009). Performance of traditional and molecular methods for detecting biological agents in drinking water. U.S. Geological Survey.

Frans, I., Lievens, B., Heusdens, C., \& Willems, K.A. (2008). Detection and identification of fish pathogens: What is the future?

Galanis, A., Kourkoutas, Y., Tassou, C.C., \& Chorianopoulos, N. 
(2015). Detection and identification of probiotic Lactobacillus plantarum strains by multiplex PCR using RAPD-derived primers. International Journal of Molecular Sciences, 16(10), 25141-25153.

Gao, H., Li, F., Zhang, X., Wang, B., \& Xiang, J. (2010). Rapid, sensitive detection of Vibrio anguillarum using loopmediated isothermal amplification. Chinese Journal of Oceanology and Limnology, 28(1), 62-66.

García-Giménez, J.L., Beltrán-García, J., Romá-Mateo, C., SecoCervera, M., Pérez-Machado, G., \& Mena-Mollá, S. (2019). Chapter 2-Epigenetic biomarkers for disease diagnosis. In S. Sharma (Ed.), Prognostic Epigenetics (Vol. 15, pp. 21-44). Academic Press. https://doi.org/10.1016/B978-0-12-814259-2.00002-9

García-González, P., García-Lamas, N., Edfuf, C.F., \& Santos, Y. (2011). Development of a PCR method for the specific identification of the marine fish pathogen Tenacibaculum soleae. Aquaculture, 319(1-2), 1-4.

Gilligan, P.H. (2013). Identification of pathogens by classical clinical tests. The Prokaryotes, E. Rosenberg, EF DeLong, S. Lory, E. Stackebrandt, and F. Thompson, Eds. (Springer Berlin Heidelberg), 57-89.

Grumaz, C., Hoffmann, A., Vainshtein, Y., Kopp, M., Grumaz, S., Stevens, P., Decker, S.O., Weigand, M.A., Hofer, S., \& Brenner, T. (2020). Rapid next-generation sequencingbased diagnostics of bacteremia in septic patients. The Journal of Molecular Diagnostics, 22(3), 405-418.

Gudding, R., Lillehaug, A., \& Evensen, Ø. (2014). Fish vaccination (Vol. 614). Wiley Online Library.

Gunimaladevi I, Kono T, Lapatra SE, Sakai M (2005) A loop mediated iso- thermal amplification (LAMP) method for detection of infectious hematopoi- etic necrosis virus (IHNV) in rainbow trout (Oncorhynchus mykiss). Archives of Virology 150, 899-909

Gunimaladevi I, Kono T, Venugopal MN, Sakai M (2004) Detection of koi herpesvirus in common carp, Cyprinus carpio L., by loop-mediated isother- mal amplification. Journal of Fish Diseases 27, 583-589

Gunson, R.N., Collins, T.C., \& Carman, W.F. (2006). Practical experience of high throughput real time PCR in the routine diagnostic virology setting. Journal of Clinical Virology, 35(4), 355-367.

Haldar, S., Maharajan, A., Chatterjee, S., Hunter, S.A., Chowdhury, N., Hinenoya, A., Asakura, M., \& Yamasaki, S. (2010). Identification of Vibrio harveyi as a causative bacterium for a tail rot disease of sea bream Sparus aurata from research hatchery in Malta. Microbiological Research, 165(8), 639-648.

Hallett, S.L., \& Bartholomew, J.L. (2006). Application of a realtime PCR assay to detect and quantify the myxozoan parasite Ceratomyxa shasta in river water samples. Diseases of Aquatic Organisms, 71(2), 109-118.

Hanna, S.E., Connor, C.J., \& Wang, H.H. (2005). Real-time polymerase chain reaction for the food microbiologist: Technologies, applications, and limitations. Journal of Food Science, 70(3), R49-R53.

Haras, D., \& Amoros, J.P. (1994). Polymerase chain reaction, cold probes and clinical diagnosis. Sante (Montrouge, France), 4(1), 43-52.

Hayden, M.J., Nguyen, T.M., Waterman, A., \& Chalmers, K.J. (2008). Multiplex-ready PCR: A new method for multiplexed SSR and SNP genotyping. BMC Genomics, 9(1), 1-12.

Henriksson, P.J., Rico, A., Troell, M., Klinger, D.H., Buschmann, A.H., Saksida, S., Chadag, M.V., \& Zhang, W. (2018).
Unpacking factors influencing antimicrobial use in global aquaculture and their implication for management: A review from a systems perspective. Sustainability Science, 13(4), 1105-1120.

Herrero, B., Vieites, J.M., \& Espiñeira, M. (2011). Detection of anisakids in fish and seafood products by real-time PCR. Food Control, 22(6), 933-939.

Hiney, M., Dawson, M.T., Heery, D.M., Smith, P.R., Gannon, F., \& Powell, R. (1992). DNA probe for Aeromonas salmonicida. Applied and Environmental Microbiology, 58(3), 1039-1042.

Hommelsheim, C.M., Frantzeskakis, L., Huang, M., \& Ülker, B. (2014). PCR amplification of repetitive DNA: A limitation to genome editing technologies and many other applications. Scientific Reports, 4(1), 1-13.

Hong, G.-E., Kim, D.-G., Bae, J.-Y., Ahn, S.-H., Bai, S. C., \& Kong, I.-S. (2007). Species-specific PCR detection of the fish pathogen, Vibrio anguillarum, using the amiB gene, which encodes $\mathrm{N}$-acetylmuramoyl-L-alanine amidase. FEMS Microbiology Letters, 269(2), 201-206.

Houpikian, P., \& Raoult, D. (2002). Traditional and molecular techniques for the study of emerging bacterial diseases: One laboratory's perspective. Emerging Infectious Diseases, 8(2), 122.

$\mathrm{Hu}$, Y. (2018). Molecular techniques for blood and blood product screening. Advanced Techniques in Diagnostic Microbiology, 31-66.

Huntingford, F.A., \& Kadri, S. (2014). Defining, assessing and promoting the welfare of farmed fish. Revue Scientifique et Technique (International Office of Epizootics), 33(1), 233-244.

Hwang, J.Y., Lee, S., Priyathilaka, T.T., Yang, H., Kwon, H., Kwon, M.G., Hwang, S.D., Kim, M.-J., \& Lee, J. (2018). Phylogenetic analysis and duplex RT-PCR detection of viral hemorrhagic septicemia virus in olive flounder (Paralichthys olivaceus) from Korea. Aquaculture, 484, 242-249.

Inglis, V., \& Aoki, T. (1996). Rapid identification of Aeromonas salmonicida subspecies salmonicida by the polymerase chain reaction. Aquaculture, 141(1-2), 13-24.

Isaksen, T.E., Karlsbakk, E., Repstad, O., \& Nylund, A. (2012). Molecular tools for the detection and identification of Ichthyobodo spp.(Kinetoplastida), important fish parasites. Parasitology International, 61(4), 675-683.

Izumi, S., H. Fujii, Aranishi, F. (2005) Detection and identification of Flavobac- terium psychrophilum from gill washings and benthic diatoms by PCR-based sequencing analysis Journal of Fish Diseases 28, 559-564

Izumi S, Yamamoto M, Suzuki K, Shimizu A, Aranishi F (2007) Identifica- tion and detection of Pseudomonas plecoglossicida isolates with PCR pri- mers targeting the gyrB region. Journal of Fish Diseases 30, 391-397

Jeong, J.B., Park, K.H., Kim, H.Y., Hong, S.H., Kim, K.H., Chung, J.-K., Komisar, J.L., \& Do Jeong, H. (2004). Multiplex PCR for the diagnosis of red sea bream iridoviruses isolated in Korea. Aquaculture, 235(1-4), 139-152.

Jiménez, A., Tibatá, V.M., Junca, H., Ariza, F., Verjan, N., \& Iregui, C. (2011). Evaluating a nested-PCR assay for detecting Streptococcus agalactiae in red tilapia (Oreochromis sp.) tissue. Aquaculture, 321, 203-206.

Jousson, O., Pretti, C., Di Bello, D., \& Cognetti-Varriale, A.M. (2005). Non-invasive detection and quantification of the parasitic ciliate Ichthyophthirius multifiliis by real-time PCR. Diseases of Aquatic Organisms, 65(3), 251-255.

Kadri, K. (2019). Polymerase chain reaction (PCR): Principle 
and applications. In Synthetic Biology-New Interdisciplinary Science. IntechOpen.

Kalle, E., Kubista, M., \& Rensing, C. (2014). Multi-template polymerase chain reaction. Biomolecular Detection and Quantification, 2, 11-29.

Kamolvarin, N., Tirawatnpong, T., Rattanasiwamoke, R., Tirawatnpong, S., Panpanich, T., \& Hemachudha, T. (1993). Diagnosis of rabies by polymerase chain reaction with nested primers. The Journal of infectious diseases, 167(1), 207-210.

Kechin, A., Borobova, V., Boyarskikh, U., Khrapov, E., Subbotin, S., \& Filipenko, M. (2020). NGS-PrimerPlex: Highthroughput primer design for multiplex polymerase chain reactions. PLOS Computational Biology, 16(12), e1008468.

Keeling, S.E., Johnston, C., Wallis, R., Brosnahan, C.L., Gudkovs, N., \& McDonald, W.L. (2012). Development and validation of real-time PCR for the detection of Yersinia ruckeri. Journal of Fish Diseases, 35(2), 119-125.

Kelley, G.O., Adkison, M.A., Zagmutt-Vergara, F.J., Leutenegger, C.M., Bethel, J.W., Myklebust, K.A., McDowell, T.S., \& Hedrick, R.P. (2006). Evaluation of quantitative real-time PCR for rapid assessments of the exposure of sentinel fish to Myxobolus cerebralis. Parasitology Research, 99(4), 328-335.

Kelley, G.O., Zagmutt-Vergara, F.J., Leutenegger, C.M., Myklebust, K.A., Adkison, M.A., McDowell, T.S., Marty, G.D., Kahler, A.L., Bush, A.L., \& Gardner, I.A. (2004). Evaluation of five diagnostic methods for the detection and quantification of Myxobolus cerebralis. Journal of Veterinary Diagnostic Investigation, 16(3), 202-211.

Kermekchiev, M.B., Kirilova, L.I., Vail, E.E., \& Barnes, W.M. (2009). Mutants of Taq DNA polymerase resistant to PCR inhibitors allow DNA amplification from whole blood and crude soil samples. Nucleic acids research, 37(5), e40. https://doi.org/10.1093/nar/gkn1055

Kijewska, A., Rokicki, J., Sitko, J., \& Węgrzyn, G. (2002). Ascaridoidea: A simple DNA assay for identification of 11 species infecting marine and freshwater fish, mammals, and fish-eating birds. Experimental Parasitology, 101(1), 35-39.

Klein, D. (2002). Quantification using real-time PCR technology: Applications and limitations. Trends in Molecular Medicine, 8(6), 257-260.

Kociolek, L.K. (2017). Strategies for optimizing the diagnostic predictive value of Clostridium difficile molecular diagnostics. Journal of Clinical Microbiology, 55(5), 1244-1248.

Kokkattunivarthil, S., Krishnan, R., Kezhedath, J., \& Prasad, K. P. (2018). New set of PCR primers for SYBR green-based qPCR detection of IMNV in India. Aquaculture, 495, 726730 .

Komarudin, O., \& Slembrouck, J. (2003). Fish health management. Technical Manual for Artificial Propagation of the Indonesian Catfish, Pangasius Djambal, 109.

Kralik, P., \& Ricchi, M. (2017). A basic guide to real time PCR in microbial diagnostics: Definitions, parameters, and everything. Frontiers in Microbiology, 8, 108.

Krawczyk, B., \& Kur, J. (2018). Chapter 16 - Molecular Identification and Genotyping of Staphylococci: Genus, Species, Strains, Clones, Lineages, and Interspecies Exchanges. In V. Savini (Ed.), Pet-To-Man Travelling Staphylococci (pp. 199-223). Academic Press. https://doi.org/10.1016/B978-0-12-813547-1.00016-9
Krishna, N.K., \& Cunnion, K.M. (2012). Role of molecular diagnostics in the management of infectious disease emergencies. Medical Clinics, 96(6), 1067-1078.

Kulkarni, A., Caipang, C.M.A., Brinchmann, M.F., Korsnes, K., \& Kiron, V. (2009). Use of loop-mediated isothermal amplification assay for the detection of Vibrio anguillarum $\mathrm{O} 2 \beta$, the causative agent of vibriosis in Atlantic cod, Gadus morhua. Journal of Rapid Methods \& Automation in Microbiology, 17(4), 503-518.

Kumar, N.S., \& Gurusubramanian, G. (2011). Random amplified polymorphic DNA (RAPD) markers and its applications. Sci. Vis, 11(3), 116-124.

Kumar, V., Roy, S., Barman, D., \& Kumar, A. (2014). Immunoserological and molecular techniques used in fish disease diagnosis: A mini review. Int J Fish Aquat, 1(3), 111-117.

Kumari, N., \& Thakur, S.K. (2014). Randomly amplified polymorphic DNA-a brief review. American Journal of Animal and Veterinary Sciences, 9(1), 6-13.

Lakshmi, B., Viswanath, B., \& Sai Gopal, D.V.R. (2013). Probiotics as antiviral agents in shrimp aquaculture. Journal of Pathogens, 2013.

León, G., Maulén, N., Figueroa, J., Villanueva, J., Rodríguez, C., Vera, M.I., \& Krauskopf, M. (1994). A PCR-based assay for the identification of the fish pathogen Renibacterium salmoninarum. FEMS Microbiology Letters, 115(2-3), 131-136.

Leung, T.L., \& Bates, A.E. (2013). More rapid and severe disease outbreaks for aquaculture at the tropics: Implications for food security. Journal of Applied Ecology, 50(1), 215-222.

Levy, M.G., Poore, M.F., Colorni, A., Noga, E.J., Vandersea, M.W., \& Litaker, R.W. (2007). A highly specific PCR assay for detecting the fish ectoparasite Amyloodinium ocellatum. Diseases of Aquatic Organisms, 73(3), 219226.

Lievens, B., Frans, I., Heusdens, C., Justé, A., Jonstrup, S.P., Lieffrig, F., \& Willems, K. A. (2011a). Rapid detection and identification of viral and bacterial fish pathogens using a DNA array-based multiplex assay. Journal of Fish Diseases, 34(11), 861-875.

Lievens, B., Frans, I., Heusdens, C., Justé, A., Jonstrup, S.P., Lieffrig, F., \& Willems, K. A. (2011b). Rapid detection and identification of viral and bacterial fish pathogens using a DNA array-based multiplex assay. Journal of Fish Diseases, 34(11), 861-875.

Lindahl, J.F., \& Grace, D. (2015). The consequences of human actions on risks for infectious diseases: A review. Infection Ecology \& Epidemiology, 5(1), 30048.

Liu, L., Ge, M., Zheng, X., Tao, Z., Zhou, S., \& Wang, G. (2016). Investigation of Vibrio alginolyticus, $V$. harveyi, and $V$. parahaemolyticus in large yellow croaker, Pseudosciaena crocea (Richardson) reared in Xiangshan Bay, China. Aquaculture Reports, 3, 220-224.

Llop, P., Bonaterra, A., Peñalver, J., \& López, M.M. (2000). Development of a highly sensitive nested-PCR procedure using a single closed tube for detection of Erwinia amylovora in asymptomatic plant material. Applied and environmental microbiology, 66(5), 2071-2078.

Llor, C., \& Bjerrum, L. (2014). Antimicrobial resistance: Risk associated with antibiotic overuse and initiatives to reduce the problem. Therapeutic Advances in Drug Safety, 5(6), 229-241.

Logan, J., Logan, J.M., Edwards, K.J., \& Saunders, N.A. (2009). Real-time PCR: Current technology and applications. 
Horizon Scientific Press

López, J.R., Hamman-Khalifa, A.M., Navas, J.I., \& de la Herran, R. (2011). Characterization of ISR region and development of a PCR assay for rapid detection of the fish pathogen Tenacibaculum soleae. FEMS Microbiology Letters, 324(2), 181-188.

Lorenz, T.C. (2012). Polymerase chain reaction: Basic protocol plus troubleshooting and optimization strategies. JoVE (Journal of Visualized Experiments), 63, e3998.

Lu, R.-M., Hwang, Y.-C., Liu, I.-J., Lee, C.-C., Tsai, H.-Z., Li, H.-J., \& Wu, H.-C. (2020). Development of therapeutic antibodies for the treatment of diseases. Journal of Biomedical Science, 27(1), 1-30.

Lynch, M., \& Milligan, B.G. (1994). Analysis of population genetic structure with RAPD markers. Molecular Ecology, 3(2), 91-99.

Mackay, I.M. (2007). Real-time PCR in microbiology. Caister Academic Press Norfolk, UK.

Mackay, I.M., Arden, K.E., \& Nitsche, A. (2002). Real-time PCR in virology. Nucleic Acids Research, 30(6), 1292-1305.

Maddocks, S., \& Jenkins, R. (2017). Chapter 4-Quantitative PCR: Things to consider. Understanding PCR. Academic, Boston, 45-52.

Maddocks, Sarah, \& Jenkins, R. (2017). Chapter 2-Designing and Ordering Your Polymerase Chain Reaction Primers. In Sarah Maddocks \& R. Jenkins (Eds.), Understanding PCR (pp. 11-30). Academic Press. https://doi.org/10.1016/B978-0-12-802683-0.00002-2

Magnadottir, B. (2010). Immunological control of fish diseases. Marine Biotechnology, 12(4), 361-379.

Mahoney, J.B., \& Chernesky, M.A. (1995). Multiplex polymerase chain reaction. Molecular Methods for Viral Detection. Academic Press, Inc., New York, NY, 219-237.

Manage, P. M. (2018). Heavy Use of Antibiotics in Aquaculture; Emerging Human and Animal Health Problems-A review.

Manyi-Loh, C., Mamphweli, S., Meyer, E., \& Okoh, A. (2018). Antibiotic use in agriculture and its consequential resistance in environmental sources: Potential public health implications. Molecules, 23(4), 795.

Marancik, D.P., \& Wiens, G.D. (2013). A real-time polymerase chain reaction assay for identification and quantification of Flavobacterium psychrophilum and application to disease resistance studies in selectively bred rainbow trout Oncorhynchus mykiss. FEMS Microbiology Letters, 339(2), 122-129.

Markoulatos, P., Siafakas, N., \& Moncany, M. (2002). Multiplex polymerase chain reaction: A practical approach. Journal of Clinical Laboratory Analysis, 16(1), 47-51.

Martín, M.T., Cuesta, M.J., \& Martín, L. (2014). Development of SCAR primers for PCR assay to detect Diplodia seriata. International Scholarly Research Notices, 2014.

Marton, S., \& Eszterbauer, E. (2012). The susceptibility of diverse species of cultured oligochaetes to the fish parasite Myxobolus pseudodispar Gorbunova (Myxozoa). Journal of Fish Diseases, 35(4), 303-314.

Marwal, A., \& Gaur, R.K. (2020). Chapter 18 - Molecular markers: Tool for genetic analysis. In A. S. Verma \& A. Singh (Eds.), Animal Biotechnology (Second Edition) (pp. 353-372). Academic Press. https://doi.org/10.1016/B978-0-12-811710-1.00016-1

Mauger, F., \& Deleuze, J.-F. (2019). Chapter 3-Technological advances in studying epigenetics biomarkers of prognostic potential for clinical research. In S. Sharma (Ed.), Prognostic Epigenetics (Vol. 15, pp. 45-83). Academic Press. https://doi.org/10.1016/B978-0-12-
814259-2.00003-0

Maurer, F.P., Christner, M., Hentschke, M., \& Rohde, H. (2017). Advances in rapid identification and susceptibility testing of bacteria in the clinical microbiology laboratory: Implications for patient care and antimicrobial stewardship programs. Infectious Disease Reports, 9(1), 18-27.

McPhearson, R.M., DePaola, A., Zywno, S.R., Motes Jr, M.L., \& Guarino, A.M. (1991). Antibiotic resistance in Gramnegative bacteria from cultured catfish and aquaculture ponds. Aquaculture, 99(3-4), 203-211.

Mendonça, H.L., Arkush, K.D. (2004) Development of PCRbased methods for detection of Sphaerothecum destruens in fish tissues. Diseases of Aquatic Or-ganisms 61, 187-197

Meyer, K., Bergmann, S.M., van der Marel, M., \& Steinhagen, D. (2012). Detection of Koi herpesvirus: Impact of extraction method, primer set and DNA polymerase on the sensitivity of polymerase chain reaction examinations. Aquaculture Research, 43(6), 835-842.

Micheli, M.R., \& Bova, R. (2013). Fingerprinting methods based on arbitrarily primed PCR. Springer Science \& Business Media.

Mittal, B., Chaturvedi, P., \& Tulsyan, S. (2013). Restriction Fragment Length Polymorphism. In S. Maloy \& K. Hughes (Eds.), Brenner's Encyclopedia of Genetics (Second Edition) (pp. 190-193). Academic Press. https://doi.org/10.1016/B978-0-12-374984-0.01314-0

Miyata, M., Aoki, T., Inglis, V., Yoshida, T., \& Endo, M. (1995). RAPD analysis of Aeromonas salmonicida and Aeromonas hydrophila. Journal of Applied Bacteriology, 79(2), 181-185.

Morganti, S., Tarantino, P., Ferraro, E., D’Amico, P., Viale, G., Trapani, D., Duso, B. A., \& Curigliano, G. (2020). Role of Next-Generation Sequencing Technologies in Personalized Medicine. In P5 eHealth: An Agenda for the Health Technologies of the Future (pp. 125-154). Springer, Cham.

Morshed, M.G., Lee, M.-K., Jorgensen, D., \& Isaac-Renton, J.L. (2007). Molecular methods used in clinical laboratory: Prospects and pitfalls. FEMS Immunology \& Medical Microbiology, 49(2), 184-191.

Mougin, J., Roquigny, R., Travers, M.-A., Grard, T., BonninJusserand, M., \& Le Bris, C. (2020). Development of a mreB-targeted real-time PCR method for the quantitative detection of Vibrio harveyi in seawater and biofilm from aquaculture systems. Aquaculture, 525, 735337.

Muldrew, K.L. (2009). Molecular diagnostics of infectious diseases. Current Opinion in Pediatrics, 21(1), 102-111.

Mullis, K., Faloona, F., Scharf, S., Saiki, R.K., Horn, G.T., \& Erlich, H. (1986). Specific enzymatic amplification of DNA in vitro: The polymerase chain reaction. Cold Spring Harbor Symposia on Quantitative Biology, 51, 263-273.

Muroga, K. (2001). Viral and bacterial diseases of marine fish and shellfish in Japanese hatcheries. Aquaculture, 202(1-2), 23-44.

Nandani, K., \& Thakur, S.K. (2014). Randomly amplified polymorphic DNA-a brief review. American Journal of Animal and Veterinary Sciences, 9(1), 6-13.

Narayana, P.S., Varalakshmi, D., Pullaiah, T., \& Rao, K.S. (2018). Research methodology in Zoology. Scientific Publishers.

Nazir, R., Rehman, S., Nisa, M., \& ali Baba, U. (2019). Exploring bacterial diversity: From cell to sequence. In Freshwater Microbiology (pp. 263-306). Elsevier. 
Neshati, H., Sheybani, F., Naderi, H., Sarvghad, M., Soltani, A.K., Efterkharpoor, E., \& Nooghabi, M.J. (2018, November 13). Diagnostic Errors in Tuberculous Patients: A Multicenter Study from a Developing Country [Research Article]. Journal of Environmental and Public Health; Hindawi. https://doi.org/10.1155/2018/1975931

Nielsen, M.E., Høi, L., Schmidt, A.S., Qian, D., Shimada, T., Shen, J.Y., \& Larsen, J.L. (2001). Is Aeromonas hydrophila the dominant motile Aeromonas species that causes disease outbreaks in aquaculture production in the Zhejiang Province of China? Diseases of Aquatic Organisms, 46(1), 23-29.

Nikiforova, M.N., LaFramboise, W.A., \& Nikiforov, Y.E. (2015). Amplification-Based Methods. In Clinical genomics (pp. 57-67). Elsevier.

Nisaa, K., Sukenda, Z.M., Nuryati, S., \& Lusiastuti, A.M. (2017). Fry tilapia Oreochromis niloticus antibody improvement against Streptococcus agalactiae through broodstock vaccination. Pakistan Journal of Biotechnology, 14, 9-16.

Noga, E.J. (2010). Fish disease: Diagnosis and treatment. John Wiley \& Sons.

Notomi, T., Okayama, H., Masubuchi, H., Yonekawa, T., Watanabe, K., Amino, N., \& Hase, T. (2000). Loopmediated isothermal amplification of DNA. Nucleic acids research, 28(12), E63.

https://doi.org/10.1093/nar/28.12.e63

Nuchprayoon, S., Junpee, A., \& Poovorawan, Y. (2007). Random amplified polymorphic DNA (RAPD) for differentiation between Thai and Myanmar strains of Wuchereria bancrofti. Filaria Journal, 6(1), 1-8.

Nygren, M. (2000). Molecular diagnostics of infectious diseases [PhD Thesis]. Bioteknologi.

Opiyo, M.A., Marijani, E., Muendo, P., Odede, R., Leschen, W., \& Charo-Karisa, H. (2018). A review of aquaculture production and health management practices of farmed fish in Kenya. International Journal of Veterinary Science and Medicine, 6(2), 141-148.

Orakpoghenor, O., \& Markus, T. (2020). Diagnostic Techniques in Molecular Biology -An Overview. 1, 1008.

Osorio, C.R., Collins, M.D., Toranzo, A.E., Barja, J.L., \& Romalde, J.L. (1999). 16S rRNA gene sequence analysis of Photobacterium damselae and nested PCR method for rapid detection of the causative agent of fish pasteurellosis. Applied and environmental microbiology, 65(7), 2942-2946.

Osorio, C.R., Toranzo, A.E., Romalde, J.L., \& Barja, J.L. (2000) Multiplex PCR assay for urea and $16 \mathrm{~S}$ rRNA genes clearly discriminates between both subspecies of Photobacterium damselae. Diseases of Aquatic Organisms 40, 177-183

Pallas, V., Sanchez-Navarro, J., Varga, A., Aparicio, F., \& James, D. (2009). Multiplex polymerase chain reaction (PCR) and real-time multiplex PCR for the simultaneous detection of plant viruses. In Plant Pathology (pp. 193208). Springer.

Pang, L., Zhang, X.-H., Zhong, Y., Chen, J., Li, Y., \& Austin, B. (2006). Identification of Vibrio harveyi using PCR amplification of the toxR gene. Letters in Applied Microbiology, 43(3), 249-255.

Paoletti, M., Mattiucci, S., Colantoni, A., Levsen, A., Gay, M., \& Nascetti, G. (2018). Species-specific Real Time-PCR primers/probe systems to identify fish parasites of the genera Anisakis, Pseudoterranova and Hysterothylacium (Nematoda: Ascaridoidea). Fisheries Research, 202, 38-
48.

Park, M., Won, J., Choi, B.Y., \& Lee, C.J. (2020). Optimization of primer sets and detection protocols for SARS-CoV-2 of coronavirus disease 2019 (COVID-19) using PCR and realtime PCR. Experimental \& Molecular Medicine, 52(6), 963-977.

Patrinos, G.P., Danielson, P.B., \& Ansorge, W.J. (2017). Chapter 1 - Molecular Diagnostics: Past, Present, and Future. In George P. Patrinos (Ed.), Molecular Diagnostics (Third Edition) (pp. 1-11). Academic Press. https://doi.org/10.1016/B978-0-12-802971-8.00001-8

Peterson, E., \& Kaur, P. (2018). Antibiotic resistance mechanisms in bacteria: Relationships between resistance determinants of antibiotic producers, environmental bacteria, and clinical pathogens. Frontiers in Microbiology, 9, 2928.

Plumb, J.A., \& Hanson, L.A. (2010). Health maintenance and principal microbial diseases of cultured fishes. John Wiley \& Sons.

Pontes, T., D'Amelio, S., Costa, G., \& Paggi, L. (2005). Molecular characterization of larval anisakid nematodes from marine fishes of Madeira by a PCR-based approach, with evidence for a new species. Journal of Parasitology, 91(6), 1430-1434.

Preena, P.G., Swaminathan, T.R., Kumar, V.J.R., \& Singh, I.S.B. (2020). Antimicrobial resistance in aquaculture: A crisis for concern. Biologia, 1-21.

Premkrishnan, B.V., \& Arunachalam, V. (2012). In silico RAPD priming sites in expressed sequences and iSCAR markers for oil palm. Comparative and Functional Genomics, 2012.

Pridgeon, J.W., \& Klesius, P.H. (2012). Major bacterial diseases in aquaculture and their vaccine development. Anim. Sci. Rev, 7, 1-16.

Procop, G.W. (2007). Molecular diagnostics for the detection and characterization of microbial pathogens. Clinical Infectious Diseases, 45(Supplement_2), S99-S111.

Radich, J. (2000). Multiplex Polymerase Chain Reaction. In R. Rapley (Ed.), The Nucleic Acid Protocols Handbook (pp. 619-623). Humana Press. https://doi.org/10.1385/159259-038-1:619

Rahman, M.K. (2013). Impact of aquaculture drugs and chemicals on aquatic ecology and productivity. Bangladesh Fisheries Research Institute, Ministry of Fisheries and Livestock.

Rao, M.B., Tanksale, A.M., Ghatge, M.S., \& Deshpande, V.V. (1998). Molecular and biotechnological aspects of microbial proteases. Microbiology and Molecular Biology Reviews, 62(3), 597-635.

Ravelo, C., Magarinos, B., López-Romalde, S., Toranzo, A. E., \& Romalde, J.L. (2003). Molecular fingerprinting of fishpathogenic Lactococcus garvieae strains by random amplified polymorphic DNA analysis. Journal of Clinical Microbiology, 41(2), 751-756.

Rehman, S., Gora, A.H., Ahmad, I., \& Rasool, S.I. (2017). Stress in aquaculture hatcheries: Source, impact and mitigation. International Journal of Current Microbiology and Applied Sciences, 6, 3030-3045.

Rhoads, D.D., Wolcott, R.D., Sun, Y., \& Dowd, S.E. (2012). Comparison of Culture and Molecular Identification of Bacteria in Chronic Wounds. International Journal of Molecular Sciences, 13(3), 2535-2550. https://doi.org/10.3390/ijms13032535

Rimstad, E., Krona, R., Hornes, E., Olsvik, Ø., \& Hyllseth, B. (1990). Detection of infectious pancreatic necrosis virus 
(IPNV) RNA by hybridization with an oligonucleotide DNA probe. Veterinary Microbiology, 23(1), 211-219. https://doi.org/10.1016/0378-1135(90)90151-K

Rocco, L., Valentino, I.V., Scapigliati, G., \& Stingo, V. (2014). RAPD-PCR analysis for molecular characterization and genotoxic studies of a new marine fish cell line derived from Dicentrarchus labrax. Cytotechnology, 66(3), 383393.

Rodger, H.D. (2016). Fish disease causing economic impact in global aquaculture. In Fish vaccines (pp. 1-34). Springer.

Rokicka, M., Lumme, J., \& Ziętara, M.S. (2007). Identification of Gyrodactylus ectoparasites in Polish salmonid farms by PCR-RFLP of the nuclear ITS segment of ribosomal DNA (Monogenea, Gyrodactylidae). Acta Parasitologica, 52(3), 185-195.

Rollinson, D., \& Hay, S.I. (2012). Advances in parasitology (Vol. 79). Academic Press

Rychlik, W., Spencer, W.J., \& Rhoads, R.E. (1990). Optimization of the annealing temperature for DNA amplification in vitro; Nucleic Acids Research, 18(21), 6409-6412. https://doi.org/10.1093/nar/18.21.6409

Sadler, J., \& Goodwin, A. (2007). Disease prevention on fish farms. Southern Regional Aquaculture Center.

Sahoo, P.K., Mohanty, J., Garnayak, S.K., Mohanty, B.R., Kar, B., Jena, J., \& Prasanth, H. (2013). Genetic diversity and species identification of Argulus parasites collected from major aquaculture regions of India using RAPD-PCR. Aquaculture Research, 44(2), 220-230.

Sambrook, J. (2001). Molecular cloning: A laboratory manual/Joseph Sambrook, David W. Russell. Cold Spring Harbor, NY: Cold Spring Harbor Laboratory.

Santos, L., \& Ramos, F. (2018). Antimicrobial resistance in aquaculture: Current knowledge and alternatives to tackle the problem. International Journal of Antimicrobial Agents, 52(2), 135-143.

Sarker, J., \& Faruk, M.A.R. (2016). Experimental infection of Aeromonas hydrophila in pangasius. Progressive Agriculture, 27(3), 392-399.

Sarowar, M.N., Hossain, M.J., Nasrin, T., Naznin, T., Hossain, Z., \& Rahman, M.M. (2019). Molecular identification of oomycete species affecting aquaculture in Bangladesh. Aquaculture and Fisheries, 4(3), 105-113.

Savan R, Igarashi A, Matsuoka S, Sakai M (2004) Sensitive and rapid detection of edwardsiellosis in fish by a loopmediated isothermal amplification method. Applied and Environmental Microbiology 70, 621-624

Seo, J.S., Jeon, E.J., Kim, M.S., Woo, S.H., Do Kim, J., Jung, S.H., Park, M.A., Jee, B.Y., Kim, J.W., \& Kim, Y.-C. (2012). Molecular identification and real-time quantitative PCR (qPCR) for rapid detection of Thelohanellus kitauei, a myxozoan parasite causing intestinal giant cystic disease in the Israel carp. The Korean Journal of Parasitology, 50(2), 103.

Serrano, P.H. (2005). Responsible use of antibiotics in aquaculture (Vol. 469). Food \& Agriculture Org.

Serwecińska, L. (2020). Antimicrobials and Antibiotic-Resistant Bacteria: A Risk to the Environment and to Public Health. Water, 12(12), 3313.

Shaheen Shahzad, M.A., Sikandar, S., \& Afzal, I. (2020). Polymerase Chain Reaction. Genetic Engineering: $A$ Glimpse of Techniques and Applications, 13.

Sharma, M., Shrivastav, A.B., Sahni, Y.P., \& Pandey, G. (2012). Overviews of the treatment and control of common fish diseases.

Shekhawat, S.S., Gaurav, A., Joseph, B., Kumar, H., \& Kumar, N. (2019). Random amplified polymorphic DNA-based molecular heterogeneity analysis of Salmonella enterica isolates from foods of animal origin. Veterinary World, 12(1), 146.

Shen, C.-H. (2019a). Chapter 9-Amplification of Nucleic Acids. In C.-H. Shen (Ed.), Diagnostic Molecular Biology (pp. 215-247). Academic Press. https://doi.org/10.1016/B978-0-12-802823-0.00009-2

Shen, C.-H. (2019b). Chapter 15-Molecular Diagnosis of Infectious Diseases. In C.-H. Shen (Ed.), Diagnostic Molecular Biology (pp. 387-411). Academic Press. https://doi.org/10.1016/B978-0-12-802823-0.00015-8

Shivappa RB, Savan R, Kono T, Sakai M, Emmenegger E, Kurath $G$, Le- vine JF (2008) Detection of spring viraemia of carp virus (SVCV) by loop- mediated isothermal amplification (LAMP) in koi carp, Cyprinus carpio L. Journal of Fish Diseases 31, 249-258

Siddiqui, M.Z. (2010). Monoclonal antibodies as diagnostics; an appraisal. Indian Journal of Pharmaceutical Sciences, 72(1), 12.

Sint, D., Raso, L., \& Traugott, M. (2012). Advances in multiplex PCR: Balancing primer efficiencies and improving detection success. Methods in Ecology and Evolution, 3(5), 898-905.

Skirpstunas RT, Hergert JM, Baldwin TJ (2006) Detection of early stages of Myxobolus cerebralis in fin clips from rainbow trout (Oncorhynchus mykiss). Journal of Veterinary Diagnostic Investigation 18, 274-277

Smith, P. (2008). Antimicrobial resistance in aquaculture. Revue Scientifique et Technique (International Office of Epizootics), 27(1), 243-264.

Soliman H, El-Matbouli M (2006) Reverse transcription loopmediated iso- thermal amplification (RT-LAMP) for rapid detection of viral hemorrhagic septicaemia virus (VHS). Veterinary Microbiology 114, 205-213

Soto, E., Bowles, K., Fernandez, D., \& Hawke, J.P. (2010). Development of a real-time PCR assay for identification and quantification of the fish pathogen Francisella noatunensis subsp. Orientalis. Diseases of Aquatic Organisms, 89(3), 199-207.

Staahlberg, A., Zoric, N., \AAman, P., \& Kubista, M. (2005). Quantitative real-time PCR for cancer detection: The lymphoma case. Expert Review of Molecular Diagnostics, 5(2), 221-230.

Tavares-Dias, M., \& Martins, M.L. (2017). An overall estimation of losses caused by diseases in the Brazilian fish farms. Journal of Parasitic Diseases, 41(4), 913-918. https://doi.org/10.1007/s12639-017-0938-y

Thornber, K., Verner-Jeffreys, D., Hinchliffe, S., Rahman, M.M., Bass, D., \& Tyler, C.R. (2019). Evaluating antimicrobial resistance in the global shrimp industry. Rev Aquacult (in press).

Thornber, K., Verner-Jeffreys, D., Hinchliffe, S., Rahman, M.M., Bass, D., \& Tyler, C.R. (2020). Evaluating antimicrobial resistance in the global shrimp industry. Reviews in Aquaculture, 12(2), 966-986.

Tom, M., Chen, N., Segev, M., Herut, B., \& Rinkevich, B. (2004). Quantifying fish metallothionein transcript by real time PCR for its utilization as an environmental biomarker. Marine Pollution Bulletin, 48(7-8), 705-710.

Tomar, R.S. (2010). Molecular markers and plant biotechnology. New India Publishing.

Torres, C., Vitalis, E.A., Baker, B.R., Gardner, S.N., Torres, M.W., \& Dzenitis, J.M. (2011). LAVA: an open-source approach to designing LAMP (loop-mediated isothermal amplification) DNA signatures. BMC bioinformatics, 12, 240. https://doi.org/10.1186/1471-2105-12-240 
Tripathy, S., Kumar, N., Mohanty, S., Samanta, M., Mandal, R.N., \& Maiti, N.K. (2007). Characterisation of Pseudomonas aeruginosa isolated from freshwater culture systems. Microbiological Research, 162(4), 391396.

Tsai, M.A., Wang, P.C., Yoshida, T., Liaw, L.L., \& Chen, S.C. (2013). Development of a sensitive and specific LAMP PCR assay for detection of fish pathogen Lactococcus garvieae. Diseases of aquatic organisms, 102(3), 225235. https://doi.org/10.3354/dao02546

Tymoczko, J.L., Berg, J.M., \& Stryer, L. (2011). Biochemistry: A short course. Macmillan.

Urdaci, M.C., Chakroun, C., Faure, D., \& Bernardet, J.-F. (1998). Development of a polymerase chain reaction assay for identification and detection of the fish pathogen Flavobacterium psychrophilum. Research in Microbiology, 149(7), 519-530.

Uzonur, I., Akdeniz, G., Katmer, Z., \& Ersoy, S.K. (2013). RAPDPCR and real-time PCR HRM based genetic variation evaluations of Urtica dioica parts, ecotypes and evaluations of morphotypes in Turkey. African Journal of Traditional, Complementary and Alternative Medicines, 10(2), 232-245.

van Pelt-Verkuil, E., Van Belkum, A., \& Hays, J.P. (2008). Principles and technical aspects of PCR amplification. Springer Science \& Business Media.

van Pelt-Verkuil, E., van Belkum, A., \& Hays, J.P. (Eds.). (2008). Analysis of PCR Amplification Products. In Principles and Technical Aspects of PCR Amplification (pp. 141-182). Springer Netherlands. https://doi.org/10.1007/978-14020-6241-4_9

Váradi, L., Luo, J.L., Hibbs, D.E., Perry, J.D., Anderson, R.J., Orenga, S., \& Groundwater, P.W. (2017). Methods for the detection and identification of pathogenic bacteria: Past, present, and future. Chemical Society Reviews, 46(16), 4818-4832.

Wages, J.M. (2005). POLYMERASE CHAIN REACTION. In P. Worsfold, A. Townshend, \& C. Poole (Eds.), Encyclopedia of Analytical Science (Second Edition) (pp. 243-250). Elsevier. https://doi.org/10.1016/B0-12-3693977/00475-1

Wakabayashi, H., Yoshida, T., Nomura, T., Nakai, T., \& Takano, T. (2016). Diseases caused by bacterial pathogens in inland water. Fish Diseases, 122-189.

Watts, J.E., Schreier, H.J., Lanska, L., \& Hale, M.S. (2017). The rising tide of antimicrobial resistance in aquaculture: Sources, sinks and solutions. Marine Drugs, 15(6), 158.

Wiklund T, Madsen L, Bruun MS, Dalsgaard I (2000) Detection of Flavo- bacterium psychrophilum from fish tissue and water samples by PCR ampli- fication. Journal of Applied Microbiology 88, 299-307
Williams, K., Blake, S., Sweeney, A., Singer, J.T., \& Nicholson, B.L. (1999). Multiplex reverse transcriptase PCR assay for simultaneous detection of three fish viruses. Journal of Clinical Microbiology, 37(12), 4139-4141.

Witteveldt, J. (2006). On the vaccination of shrimp against white spot syndrome virus.

Wolf, K. (2019). Fish viruses and fish viral diseases. Cornell University Press.

Wong, M.L., \& Medrano, J.F. (2005). Real-time PCR for mRNA quantitation. BioTechniques, 39(1), 75-85. https://doi.org/10.2144/05391RV01

Yamamoto, Y. (2002). PCR in Diagnosis of Infection: Detection of Bacteria in Cerebrospinal Fluids. Clinical and Diagnostic Laboratory Immunology, 9(3), 508-514. https://doi.org/10.1128/CDLI.9.3.508-514.2002

Yang, S., \& Rothman, R.E. (2004). PCR-based diagnostics for infectious diseases: Uses, limitations, and future applications in acute-care settings. The Lancet. Infectious Diseases, 4(6), 337-348. https://doi.org/10.1016/S1473-3099(04)01044-8

Yeh, H.-Y., Shoemaker, C.A., \& Klesius, P.H. (2006). Sensitive and rapid detection of Flavobacterium columnare in channel catfish Ictalurus punctatus by a loop-mediated isothermal amplification method. Journal of Applied Microbiology, 100(5), 919-925.

Zdzalik, M., Kalinska, M., Wysocka, M., Stec-Niemczyk, J., Cichon, P., Stach, N., Gruba, N., Stennicke, H.R., Jabaiah, A., \& Markiewicz, M. (2013). Biochemical and structural characterization of SpID protease from Staphylococcus aureus. PLoS One, 8(10), e76812.

Zebardast, N., Haghighi, A., Yeganeh, F., Tabaei, S.J.S., Gharavi, M.J., Fallahi, S., Lasjerdi, Z., Salehi, N., Taghipour, N., \& Kohansal, C. (2014). Application of multiplex PCR for detection and differentiation of Entamoeba histolytica, Entamoeba dispar and Entamoeba moshkovskii. Iranian Journal of Parasitology, 9(4), 466.

Zhou, Y. Xiao, J. Ma, X. Wang, Q. \& Zhang, Y. (2018). An effective established biosensor of bifunctional probeslabeled AuNPs combined with LAMP for detection of fish pathogen Streptococcus iniae. Applied microbiology and biotechnology, 102(12), 5299-5308. https://doi.org/10.1007/s00253-018-9016-3

Zhu, X. Gasser, R.B. Podolska, M. \& Chilton, N.B. (1998). Characterisation of anisakid nematodes with zoonotic potential by nuclear ribosomal DNA sequences. International Journal for Parasitology, 28(12), 19111921.

Zia, Q., Alawami, M., Mokhtar, N.F.K., Nhari, R.M.H.R. \& Hanish, I. (2020). Current analytical methods for porcine identification in meat and meat products. Food Chemistry, 324, 126664. 